
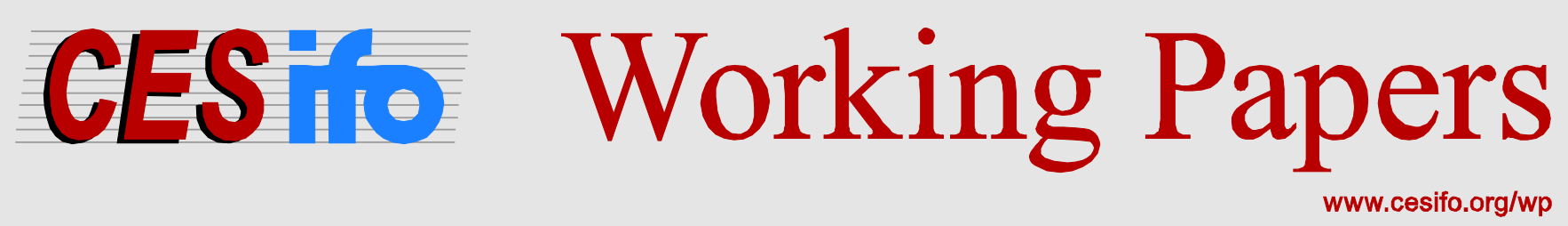

\title{
Growing Groups, Cooperation, and the Rate of Entry
}

\author{
Eva Ranehill \\ Frédéric Schneider \\ Roberto A. Weber
}

CESIFO WORKING PAPER NO. 4719

CATEGORY 13: BEHAVIOURAL ECONOMICS

MARCH 2014

An electronic version of the paper may be downloaded

- from the SSRN website:

- from the RePEc website:

- from the CESifo website:

WWW.SSRN.com

www.RePEc.org

www.CESifo-group.org/wp

\section{CESifo}




\title{
Growing Groups, Cooperation, and the Rate of Entry
}

\begin{abstract}
We study the stability of voluntary cooperation in response to varying rates at which a group grows. Using a laboratory public-good game with voluntary contributions and economies of scale, we construct a situation in which expanding a group's size yields potential efficiency gains, but only if the group overcomes the challenge that growth poses for sustained cooperation. We then study the effect on cooperation of exogenously varying rates of entry. Slow growth yields higher cooperation rates and welfare than fast growth, both for incumbents and entrants. This is consistent with slow growth allowing the persistence of optimistic self-reinforcing beliefs. We also study growth rates determined by incumbent group members. While such endogenous growth generally also produces high cooperation levels, growth stalls at intermediate group sizes, leaving potential efficiency gains from growth unrealized.
\end{abstract}

JEL-Code: C920, C720.

Keywords: voluntary cooperation, experiment, public good game, endogenous growth.

\author{
Eva Ranehill \\ Department of Economics \\ University of Zurich \\ Blümlisalpstrasse 10 \\ Switzerland - 8006 Zurich \\ eva.ranehill@econ.uzh.ch
}

\author{
Frédéric Schneider \\ Department of Economics \\ University of Zurich \\ Blümlisalpstrasse 10 \\ Switzerland - 8006 Zurich \\ frederic.schneider@econ.uzh.ch
}

\author{
Roberto A. Weber \\ Department of Economics \\ University of Zurich \\ Blümlisalpstrasse 10 \\ Switzerland - 8006 Zurich \\ roberto.weber@econ.uzh.ch
}

January 18, 2014

We are grateful for comments from participants at several conferences and seminars. Financial support from the Jan Wallander and Tom Hedelius Foundation is gratefully acknowledged (E. Ranehill). We also gratefully acknowledge support from the Research Priority Program "Foundations of Human Social Behavior” at the University of Zürich. 


\section{Introduction}

Groups engaged in economic activity often need to grow by incorporating new individuals. For example, firms expand by hiring new workers; the populations of nations and cities increase through immigration; and clubs, volunteer organizations, and cooperatives grow by admitting individuals as new members. Many such groups rely on norms of voluntary cooperation, whereby the group functions better when individuals forgo private benefit for improved collective outcomes. For example, the extent to which residents of a country adhere to anti-corruption norms can facilitate economic growth (Mauro 1995; Svensson 2005). Similarly, a firm can benefit from workers willing to voluntarily cooperate with one another (Rob and Zemsky 2002; Dur and Sol 2010). Therefore, it is important to understand how norms of voluntary cooperation can be maintained as groups grow.

This problem is particularly important because groups that grow are often successful ones with historically high levels of voluntary cooperation, and sustaining such high cooperation rates while adding new entrants poses an important challenge. ${ }^{1}$ Such cooperative groups often have great potential benefits from growth, though they may also face a challenge in incorporating individuals who do not share incumbent members' history of acting cooperatively. For example, a small successful start-up with a strong cooperative culture may stand much to gain through expansion, though such growth may mean incorporating new workers with recent experience in firms where cooperation is less prevalent. Or, a country with a low level of corruption and high economic performance may potentially benefit through immigration, but this may create the challenge of incorporating individuals from countries where corruption is more prevalent. In such cases, a group with strong norms of cooperation can benefit by growing, but primarily if strong cooperative norms are maintained by incumbents and adopted by entrants.

1. The idea that an increasing group size can exacerbate the difficulty of obtaining voluntary cooperation was noted by Olson (1971). More recent theoretical and experimental research demonstrates that the effect of group size on voluntarily cooperative behavior and public good provision depends on factors such as the specific production technology and its relation to group size (Chamberlin 1974; Isaac and Walker 1988; Isaac, Walker, and Williams 1994; Esteban and Ray 2001). Our research question is distinct, however, in that we hold fixed a particular production technology and consider whether the way in which a group grows from a small to a large size affects the degree of resulting voluntary cooperation in the large group. 
Our study investigates how high levels of cooperation can be sustained in growing groups. Prior research identifies mechanisms that facilitate sustained cooperation, such as peer-punishment (Fehr and Gächter 2000) and voluntary association (Page, Putterman, and Unel 2005), and these mechanisms have also been shown to be effective at facilitating cooperation in growing groups (Ahn, Isaac, and Salmon 2008; Charness and Yang 2008; Gürerk, Irlenbusch, and Rockenbach 2006). However, such mechanisms require conditioning on individuals' past behavior - for example, to sanction or exclude those who have been uncooperative previously. We study how cooperation might be sustained even when it is infeasible to condition on past individual behavior, as when cooperative behavior is not directly observable or there are unreliable records of individuals' past conduct. In such situations, are there nevertheless ways in which groups can facilitate cooperation while growing?

In particular, we study whether the rate at which a group grows can, by itself, determine the degree to which cooperative norms persist throughout the growth process and in the resulting grown group. Further, we study whether group members, when enabled to determine growth rates endogenously, manage growth efficiently. To this end, we conduct a laboratory experiment using a public good game with voluntary contributions and with economies of scale that make larger groups more efficient, but only if high cooperation levels are sustained as the group grows. To explore a particularly challenging situation, where the pitfalls to growth are high, we study a small cooperative group attempting to integrate individuals from a group with historically lower cooperation rates.

Our first two treatment conditions vary whether such growth is fast - all people move from the large group into the small one at once - or slow-only one person moves at a time and growth is spread out over several periods. Our study therefore shares features with prior experiments on minimum-effort ("weak-link") coordination games, which show that groups that grow slowly are more likely to maintain coordination on more efficient, high-effort equilibria (Weber 2006; Salmon and Weber 2011). In such contexts, slow growth is effective because it facilitates the persistence of optimistic beliefs - that others will exert high effort - that are then self-reinforcing as part of an equilibrium of the game. 
In comparison to coordination games, public good games represent a more challenging setting, where incentives to free ride prevail independently of beliefs. However, many prior studies demonstrate that beliefs are nevertheless important for cooperative behavior, due to preferences for "conditional cooperation," whereby people are willing to contribute as long as they think others will do so (Fischbacher, Gächter, and Fehr 2001; Fischbacher and Gächter 2010). Thus, the importance of beliefs for cooperative behavior suggests that slow, managed growth may also work in settings requiring voluntary cooperation. ${ }^{2}$ We show that such a hypothesis is supported in simulations of our experiment that employ a modified version of the belief-driven model of conditional cooperation in Fischbacher and Gächter (2010). In such simulations, we find that slow growth is indeed more effective for sustaining cooperation than fast growth, but only when beliefs play an important role in determining cooperative behavior.

Our experimental results support this behavioral prediction. The high levels of cooperation in the original small group deteriorate almost immediately with fast growth, but persist much longer with slow growth. This is both because incumbent group members decrease their contributions less when growth occurs slowly than when it is fast, and because entrants increase their contributions more when they move gradually than all at once. Thus, our first main result is that slow growth can be better for maintaining high levels of cooperation than fast growth. While this result is similar to that in Weber (2006), our context is a more challenging one, and one that applies to many distinct and important economic settings. An important characteristic of our work-related to the relationship between cooperation and coordination that we discuss above - is that we examine a finitely repeated social dilemma. In an indefinitely repeated game, high contributions are supported as an equilibrium strategy, so that any result regarding the benefits of slow growth could be interpreted as equilibrium selection, making the finding similar to that in Weber (2006). Therefore, the finitely repeated game, where high contributions are not self-reinforcing as part of an equilibrium, constitutes a more demanding

2. The importance of managing beliefs to obtain cooperation in public good games is also highlighted by Chaudhuri, Graziano, and Maitra (2006), who show that cooperation can be sustained when players receive advice from other subjects with previous experience with the game. 
setting to test whether higher cooperation rates can be maintained through the growth process.

We also study how groups fare when their members endogenously manage the growth trajectory. Therefore, a third treatment condition studies cooperation when growth rates are determined by members of the growing group, who vote on how many entrants to allow into the group in each period. ${ }^{3}$ We find that such growth trajectories generally sustain high levels of cooperation-comparable to those in our exogenous slow-growth condition-but that groups stop growing at relatively small sizes. Groups that grow endogenously thereby fail to realize the economies of scale associated with larger group sizes. As a result, they yield a lower aggregate welfare than groups in the (exogenous) slow-growth condition. Instead, average profits in this Voting condition are similar to the low outcome obtained in the exogenous fast-growth condition. Moreover, we find that growth is most strongly opposed by newcomers - i.e., those who started in the large, uncooperative group.

Our results demonstrate that the rate of entry into a group, absent any other mechanisms, can affect the resulting degree of cooperation after the group undergoes growth. This result is important, as it provides evidence that growing real-world groups in which voluntary cooperation is central to the groups' performance should take into account growth trajectories. Moreover, we find that individuals may be overly resistant to growth, even when slow growth is likely to increase social welfare.

The next section presents the experimental design. Section 3 presents our main hypothesis and discusses how it is supported by a simple model of conditional cooperation and adaptive beliefs. Section 4 presents the results and section 5 concludes.

3. Our study is thus related to other recent work in which players endogenously decide on institutional aspects of the game, such as sanctioning and reward mechanisms (Kosfeld, Okada, and Riedl 2009; Sutter, Haigner, and Kocher 2010), reduced return rates on non-cooperation (Aimone et al. 2013), or delegation of decision rights (Hamman, Weber, and Woon 2011). 


\section{Experimental design}

The experiment consisted of a finitely-repeated, for 36 periods, public good game with a linear voluntary contribution mechanism and varying group size. At the beginning of a session, participants were randomly allocated to independent six-person matching groups. Throughout the experiment, participants interacted only with other participants in their matching group. Within each matching group, participants played the public good game either as part of the entire six-person group or as part of two groups of varying size. In what follows we use the term "group" to refer to the specific set of between 2 and 6 individuals playing the game together in a period and, where necessary, use the term "matching group" to refer exclusively to the superordinate six-person group. The group size dynamics differed by condition and are explained later.

\subsection{The Public Good Game}

In each period, participants interacted in groups of between 2 and 6 participants. Each group member received 20 experimental currency units (ECU) that they could allocate between a common account and a private account. Allocations to the private account held their value but did not benefit other group members.

Contributions to the common account were pooled, multiplied by a factor $m$, and then evenly redistributed among all group members. The payoff of participant $i$ in period $t$ was thus determined by the formula:

$$
\pi_{i, t}=\left(20-g_{i, t}\right)+\frac{m\left(n_{t}\right)}{n_{t}} \sum_{j=1}^{n} g_{j, t}
$$

where $g_{i, t}$ denotes $i$ 's contribution to the common account in period $t, n_{t}$ is the group size in period $t$, and $m\left(n_{t}\right)$ the marginal return of the common account for the particular group size in that period.

The factor $m$ varied with the size of the group, $n$, to capture economies of scale, as 
shown in Table $1 .{ }^{4}$ For example, in a group of six, allocations to the common account were doubled $(m=2.0)$ and yielded a marginal per capita return of 0.333 . The size of the economies of scale was chosen to provide a tradeoff between producing an incentive to grow, while at the same time not rendering this decision trivial. That the marginal return increases with group size means that if everybody contributes a fixed, positive amount to the public good, large groups are more profitable, both individually and on aggregate, than small groups. Indeed, the socially efficient outcome involves a group size of six, with everyone contributing fully.

Table 1: Group Return and MPCR by group size

\begin{tabular}{lcccccc}
\hline Size of group $(n)$ & 6 & 5 & 4 & 3 & 2 & 1 \\
\hline Marginal Return $(m)$ & 2.000 & 1.800 & 1.620 & 1.458 & 1.312 & - \\
Per-person return $(m / n)$ & 0.333 & 0.360 & 0.405 & 0.486 & 0.656 & - \\
\hline
\end{tabular}

Note, however, that the per capita return diminishes with group size. This property keeps the average rent (the payoff in excess of the 20 ECU endowment) approximately constant across group sizes, for a fixed amount of total contributions. This means that if total contributions do not increase with group size, then individuals are not better off being in large groups than in smaller ones.

Whether group growth is a Pareto improvement, however, hinges on the distribution of contributions. For example, if $n$ group members contribute some positive amount, $c$, they will strictly prefer an $n$-person group to an $n+1$-person group where the additional person contributes nothing. If the sum of contributions is constant and borne equally by all group members, then all group sizes yield approximately the same individual payoff. Thus, our design creates a tension between the prospect of economies of scale and the risk of declining contributions if a group grows.

By using a game with a finite horizon, we ensure that there is only one Nash equilibrium: the dominant strategy is no contribution to the public good. This design feature

4. We employed similar economies of scale to those in the study by Charness and Yang (2008). In our case, the precise return is produced by the formula, $m(n)=2 \times 0.9^{6-n}$. In the degenerate case of a one-person "group", there was no common account and the single participant's payoff was fixed to the endowment of 20 ECU. 
differentiates our present paper from other studies that look at the effect of the speed of growth on equilibrium selection - e.g., in coordination games (Weber 2006) - and relates our findings more closely to other studies that analyze the evolution of cooperation in finitely repeated public good games, where there is a strong downward tendency on cooperation.

\subsection{The Phases}

The experiment consisted of three distinct phases. Participants were informed at the beginning of the experiment that there would be three phases, comprising a total of 36 periods of a specific "decision task," and that they would receive new instructions at the beginning of each phase. Phases one and two were always the same, to ensure a clean, ceteris paribus comparison between conditions in the third phase, which is our focus.

To create a situation in which growth poses a challenge to a cooperative group, the first two phases served to establish small groups with high levels of cooperation and larger groups with lower levels of cooperation. In Phase 3 we implemented movement from the larger group into the smaller one, and varied the rate of movement by condition. While this creates a very particular kind of situation, the key properties of our design - a small, cooperative group grows by introducing individuals without a similarly strong history of cooperation - represent both a challenging situation for studying whether groups can sustain voluntary cooperation as they grow and also shares features with many economically important situations outside the laboratory.

Phase 1 consisted only of the first period. In this phase, all six participants of a matching group played the public good game together, with $m=2$.

Phase 2 consisted of the subsequent 10 periods ( 2 through 11). At the beginning of this phase, each matching group was divided into one two-person group and one four-person group, based on contributions in Phase 1. The two group members who had contributed the most to the public good formed the "High" group, while the "Low" group consisted of the remaining four group members. ${ }^{5}$ Any critical ties in contributions were broken

\footnotetext{
5. In the experimental instructions, we refer to these groups as group "H" and group "L", respectively.
} 
randomly. This division was intended to use prior behavior to form groups likely to differ in their cooperativeness, and closely follows the method employed by Gächter and Thöni (2005) and Ambrus and Pathak (2011). ${ }^{6}$ In Phase 2, participants interacted only with the members of their respective group for all 10 periods. Phases 1 and 2 were identical across conditions.

After period 11, participants received instructions for the third and final phase, in which participants moved from the Low group into the High group. In all conditions, participants remained in their respective group for an additional three periods (12 through 14) before movement started. By this design, we can observe whether the mere anticipation of specific growth rates induces differences in cooperation among groups. In periods 15 through 21, movement from the Low group into the High group occurred under varying experimental conditions, as described below.

In all conditions, any movement into the High group was permanent. That is, once a participant moved from the Low to the High group, this participant remained in the High group for the rest of the experiment. This allows us to focus solely on the effect of entry, and to make clean comparisons between resulting fully merged groups of similar size in the two conditions. ${ }^{7}$ In much of what follows, to distinguish between two kinds of High-group members, we refer to Low-group members who moved to the High group as the "entrants" and to those participants who were originally in the High group as the "incumbents."

Following period 21, after all movement was complete, participants played a final 15 periods (periods 22 through 36) of the public good game in the same groups as in period 21. We conjectured that 15 periods would be long enough to observe participants' postgrowth behavior before the likely arrival of an end-game effect. In most cases, these groups were the six-person groups produced by completely merging the two-person and

\footnotetext{
Instructions are reproduced in the appendix.

6. Other studies use similar matching procedures in different contexts, such as Cain (1998), Charness (2000), Ahn et al. (2001) and Rigdon, McCabe, and Smith (2007).

7. Questions about the effect of non-permanent entry are, of course, important and may better represent some real-world applications. We chose to begin with the simpler question of permanent and one-way movement, and leave the more complex issue for subsequent research.
} 
four-person groups from Phase 2.

\subsection{Experimental Conditions}

The experiment consisted of three experimental treatment conditions. The only difference between conditions was in the rate of movement from the Low to the High group during periods 15 to 21 , and in how such movement was determined.

In two conditions, Fast and Slow Growth, all four participants in the Low group moved into the High group. The only difference was in the exogenously determined rate of movement.

In the Fast Growth condition, all four members of the Low group moved into the High group in period 15. The resulting six-person group then continued playing the game until period 36, which was the last period of the game.

In a second condition, Slow Growth, participants moved one at a time, in periods 15, 17, 19 and 21, from the Low group into the High group. Thus, in every other period, one randomly selected subject remaining in the Low group moved into the High group. Once growth finished, in period 21, participants remained together in the resulting six-person group for the remainder of the experiment, as in the Fast Growth condition.

In the third and final condition, Voting, participants themselves decided on the rate of growth in each period. More precisely, in periods 15 through 21, the public good game was preceded by a vote. All participants already in the High group -including any previous entrants - cast a vote on how many individuals to allow to move from the Low group into the High group in that period. Members of the High group could choose any number of entrants between 0 and the total number of participants remaining in the Low group. The number of participants actually moving was decided by the median vote. ${ }^{8}$ As in the Slow Growth condition, participants moving from the Low to the High group were randomly chosen and, following movement, remained in the High group for the remainder of the experiment. After the vote, the program moved the number of people specified

8. If the median was not an integer, the computer randomly rounded the number up or down to the nearest integer. This was explained clearly to subjects. 
by the median vote from the Low group into the High group. The resulting group sizes were displayed on participants' screens, and the computer proceeded to the public good game for that period.

Voting was allowed in all seven periods from period 15 through 21, unless all members of the Low group had already moved into the High group, in which case there was no need for additional voting. After the final voting period, participants remained in their current group until the end of the experiment. Thus, while under Fast and Slow growth all six participants ended up in the High group by period 21, the Voting condition allowed the possibility of two separate groups persisting in periods 21 through 36 .

\subsection{Subject Information}

In the initial instructions, participants were informed about actions and payoffs in the public good game, the total number of periods, and the three phases. They knew that the public good game would remain the same across all three phases, but that other aspects of the experiment would change from phase to phase, and that new detailed instructions containing specific information for a particular phase would be given at the beginning of each phase. A number of payoff and procedure comprehension questions preceded each phase, and the experiment did not proceed until all participants understood the instructions and answered the questions correctly.

In every period, participants had access to information about average levels of contributions in previous periods. Whenever participants in a matching group were divided into two different groups, participants observed average contribution levels for both groups in the matching group. That is, participants observed average contributions in both their own and in the other group. When movement occurred, participants therefore knew only the previous average contributions in the two groups, but not how much specific individuals - such as the participant(s) changing groups - had contributed. 


\subsection{Procedures}

This experiment was conducted in English at the laboratory for experimental economics at the University of Zurich. The experiment was computerized, and participants made their decisions privately and anonymously. ${ }^{9}$ In total, 252 undergraduate students from the University of Zurich and the Swiss Federal Institute of Technology in Zurich participated in the experiment. Each participant took part in only one experimental condition (i.e., a between-subjects design), resulting in 84 participants (14 matching groups) per condition. None of the participants were students in economics or psychology, and they had no previous experience with public good game experiments. A session lasted about two hours and participants were paid their earnings from six randomly chosen periods, in addition to a $15 \mathrm{CHF}$ participation payment. Participants earned approximately $50 \mathrm{CHF}$, on average.

\section{Predictions}

If individuals maximize their own profits, and this is common knowledge, standard theoretical analysis predicts contributions to be zero in every period and in all conditions. While straightforward and parsimonious, this prediction is refuted by many experiments on public good games (see, for example, Ledyard 1995; Vesterlund, forthcoming). Therefore, in what follows, we develop additional hypotheses in which varying degrees of cooperation can be sustained, which might differ between High and Low groups, and in which the degree of cooperation in the resulting merged group might vary between the Fast and Slow Growth conditions.

\subsection{Conditional Cooperation and High and Low Groups}

We first consider our attempt to create cooperative (High) and uncooperative (Low) groups, to allow us to study movement from the latter into the former. This preliminary

9. Recruitment was conducted using ORSEE (Greiner 2004). The experiment was programmed and conducted with the software z-Tree (Fischbacher 2007). 
step is achieved by Phases 1 and 2, which follow similar procedures to those employed by Gächter and Thöni (2005) and Ambrus and Pathak (2011).

We exploit the observation that many people are conditional cooperators - i.e., they are willing to cooperate if others also cooperate, but they dislike being exploited by free-riders (Fischbacher, Gächter, and Fehr 2001; Fischbacher and Gächter 2010). ${ }^{10}$ More precisely, at the beginning of Phase 2, we divide a matching group into a High group consisting of those who had previously contributed the most (in Phase 1) and a Low group consisting of those who contributed less. Thus, group membership likely partially reflects an individual's social type - strong free riders and conditional cooperators with pessimistic beliefs are likely to be in the Low group, while the High group is likely to comprise conditional cooperators with optimistic beliefs, as well as any altruists. Indeed, prior research shows that procedures similar to ours, in which initial contributions are subsequently used to form groups consisting of those who are ranked similarly in terms of contributions, reliably yield groups that are similarly ranked in terms of resulting cooperativeness (Gächter and Thöni 2005; Ambrus and Pathak 2011; Page, Putterman, and Unel 2005).

The ten-period second phase is designed to reinforce the contributions gap between the High and the Low groups by making participants repeatedly interact only within their group. Average contributions in the two groups are common knowledge for people in both groups, facilitating the formation of beliefs that the High group is cooperative while the Low group is not. Therefore, a precondition for our main hypotheses is that, in Phase 2, the High groups will obtain higher contribution rates than the Low groups.

\subsection{Entry and Slow vs. Fast Growth}

Conditional on getting the above predicted separation in contributions between High and Low groups in Phase 2, we next explore how the rate of movement influences cooperation in the High group as it grows by incorporating former Low group members, in Phase

10. Thus, both a player's preference for cooperation (i.e., whether the player is a strong (unconditional) free rider, a conditional cooperator, or an (unconditional) altruist) and beliefs (whether the player believes others will cooperate (optimist) or not (pessimist)) significantly influence behavior. 
3. Our work is motivated by the intuition that cooperation declines during the growth process to a greater extent with Fast growth than with Slow growth. Thus, the latter produces more cooperative fully-merged groups. More precisely, our main hypothesis with respect to these two treatment conditions is that, in the groups produced by incorporating all Low group members into the High group, contributions and earnings will be higher when movement is Slow rather than Fast.

This hypothesis draws inspiration from similar results on "minimum-effort" coordination games (Weber 2006; Salmon and Weber 2011). There, more efficient equilibria are selected in large groups when entrants are added slowly in comparison to groups that are large from the start or that grow quickly. This works by establishing a precedent of efficient coordination in small groups, where it is easier to do so, and then growing slowly to allow the beliefs that support efficient coordination to persist as the group grows. Our hypothesis is based on the idea that, as beliefs have been shown to be important in public good games as well-particularly, to the extent that optimistic beliefs about the cooperativeness of others are necessary for conditional cooperation (Fischbacher, Gächter, and Fehr 2001; Fischbacher and Gächter 2010) - then slow growth might similarly allow the persistence of cooperation as groups grow. Of course, this is more challenging in public good games than in coordination games, as beliefs are self-reinforcing in the latter but not in the former. ${ }^{11}$

However, while intuitively appealing, a theoretical basis for this prediction is not straightforward. ${ }^{12}$ Therefore, to more closely test whether slow growth can facilitate sustained cooperation, we conducted an agent-based simulation of our experiment, drawing from a recent model of dynamic beliefs and behavior in repeated public good games (Fischbacher and Gächter (2010), henceforth "FG"). A detailed exposition of the FG study and our simulation is in the appendix, but here we summarize the procedure and

11. One possible design feature is to directly elicit beliefs in the experiment. While beliefs are a potentially valuable complement to choice data, which is our primary focus, introducing incentivized belief elicitation would have complicated an experiment that was already long and complex.

12. For example, the only equilibrium model of repeated public good games with heterogeneous players of which we are aware, Ambrus and Pathak (2011), does not immediately predict a difference in contribution paths between slowly and quickly grown groups, provided that type composition and remaining periods are the same. 
results.

Instead of analyzing the game in an equilibrium model, FG posit that participants' strategies are jointly determined by their beliefs about others' contributions and by a profile of behavioral responses to expected contributions by others. ${ }^{13}$ They conducted an experiment with 140 participants, where they directly measured the beliefs and preferences of the participants in their sample. From these data, FG empirically derive a contribution function-i.e., a mapping from all possible beliefs into contributions - and a function through which beliefs are updated. FG show that this model and the elicited preferences and beliefs from their laboratory experiment do a good job of explaining dynamics in repeated public good game.

To see whether Slow growth can produce higher contributions than Fast growth, under reasonable behavioral assumptions, we develop a simulation of our experiment that employs FG's general conceptual framework and the specific individual characteristics of the 140 participants in FG's dataset. We use this information to simulate "participation" by their participants in our experiment. ${ }^{14}$

Specifically, for each run of the simulation, we sampled six participants of the original FG study. We took the contribution preferences and original beliefs as measured by FG, as well as the preferred specifications that FG estimated for the two equations that govern the evolution of the participants' beliefs and contributions over time. We then simulated our own experiment: participants "played" one period of a six-person public good game and were then separated into a four-person Low group and a two-person High group, according to their simulated first-period contributions. Contributions in the two groups evolved separately for the next 14 periods, corresponding to Phases 1 and

13. FG do not provide a model of utility maximizing individuals. Instead, the utility function is implicit in a subject's behavioral responses to a given set of beliefs. For example, "selfish" players are modeled as always contributing zero, regardless of their belief about the other participants' preferences. Similarly, beliefs are not formed rationally, but adapt linearly to new information.

14. There are important differences between FG's experiment and ours. FG study a four-person public good game with a fixed marginal return of 1.6 (per-person return of 0.4 ) and groups are randomly reassigned in every of the 10 periods. Therefore, we do not expect precise quantitative predictions for our study from these simulations, because of such differences between the two experiments. Instead, our aim is to see whether slow growth can facilitate sustained cooperation, using simple, empirically-validated assumptions about behavior, in a model in which beliefs play a central role. 
2 of our experiment. Then, starting in period 15, we ran both the Fast and the Slow conditions with the same simulated six-person group, moving all Low group members to the High group at once in the former case, and one randomly selected Low group member separately every other period in the latter case. To evaluate the effect of our simulated treatment conditions, we focus on period 21 , following the conclusion of all growth in either condition, and compare average contributions in the Slow condition with average contributions in the Fast condition, within the same simulation run. After conducting 1000 such simulation runs, we find a treatment effect in favor of the Slow condition: 579 runs produce higher average contributions in the Slow condition than in the Fast condition, 355 runs produce lower average contributions. ${ }^{15}$ Moreover, the main reason that Slow growth works better than Fast growth in this simulation is that it allows beliefs to persist regarding the high level of cooperativeness in the High group.

To gain more insight into the mechanics of this effect, and to test the robustness of the result, we also systematically varied the coefficients in the two equations that produce the dynamics of the model. This variation reveals that versions of the model in which beliefs update slowly and in which beliefs play a larger role in determining contributions are also those in which our hypothesized result occurs more regularly (see appendix for details). Thus, our conjecture that, as in coordination games, the management of beliefs through slow growth can facilitate cooperation in public good games has some support. ${ }^{16}$

\subsection{Voting}

We introduced the voting treatment as an exploratory test of whether participants, when given the opportunity to endogenously determine the growth trajectory, will do so efficiently. Given the economies of scale built into the experiment design, whether growth is optimal depends on its effect on average contributions. We were also interested in what factors influence the decision to vote for faster, or slower, growth, such as participants'

15. A small number of runs, 66 , result in no difference.

16. We observe the same general downward trend in contributions as FG, due to the free riders and "imperfect" conditional cooperators in the population. Therefore, in later periods, all groups arrive at zero contributions and the treatment difference vanishes. 
individual characteristics or the experienced game history.

\section{Results}

In analyzing the results, we first consider whether our manipulation in Phases 1 and 2, before any movement between groups, succeeds in producing High groups with greater cooperation than Low groups. We then study whether the Slow growth condition yields higher cooperation rates than the Fast growth condition, our main hypothesis. Next, we consider, separately, the behavior of entrants and incumbents, how they react to the group transitions, as well as the resulting earnings for these two kinds of participants. Finally, we present the endogenously determined growth trajectories, contributions, and earnings in the Voting condition.

\subsection{Are High Groups More Cooperative than Low Groups in}

\section{Phase 2?}

Figure 1 reports average contributions to the public good, in both Fast and Slow conditions, across periods. The two panels report data, separately, for those participants originally in the Low group (entrants) and those originally in the High group (incumbents) and track these participants across time. Table 2 presents average contributions within a particular group, Low or High, aggregated across several natural divisions of periods in the experiment. ${ }^{17}$

Looking at Phase 2 (periods 2-11), we see that contributions are significantly higher in High groups than in Low groups, as we expected. On average, contribution levels in

17. Period 1 corresponds to Phase 1 . We divide Phase 2 into two five-period blocks $(2-6,7-11)$ to identify possible differences between early and late behavior in this phase. Periods 12-14 correspond to the phase during which participants were aware of movement, and how it would occur in their particular treatment condition, but before movement actually commenced. The six-period block 15-20 corresponds to when movement is complete in the Fast condition (all four participants moved from the Low Group into the High Group in period 15), but is still in progress in the Slow condition, where participants move in periods 15, 17, 19 and 21. We then also use a six-period block (21-26) to identify the first six periods in which movement is complete in both the Slow and Fast conditions. Finally, periods 27-36 correspond to the final 10 periods of the experiment, when end-game effects arise (see Figure 1). 
Figure 1: Contribution over time for incumbents and entrants across conditions. Bars represent standard errors. Unit of observation $=$ matching group.

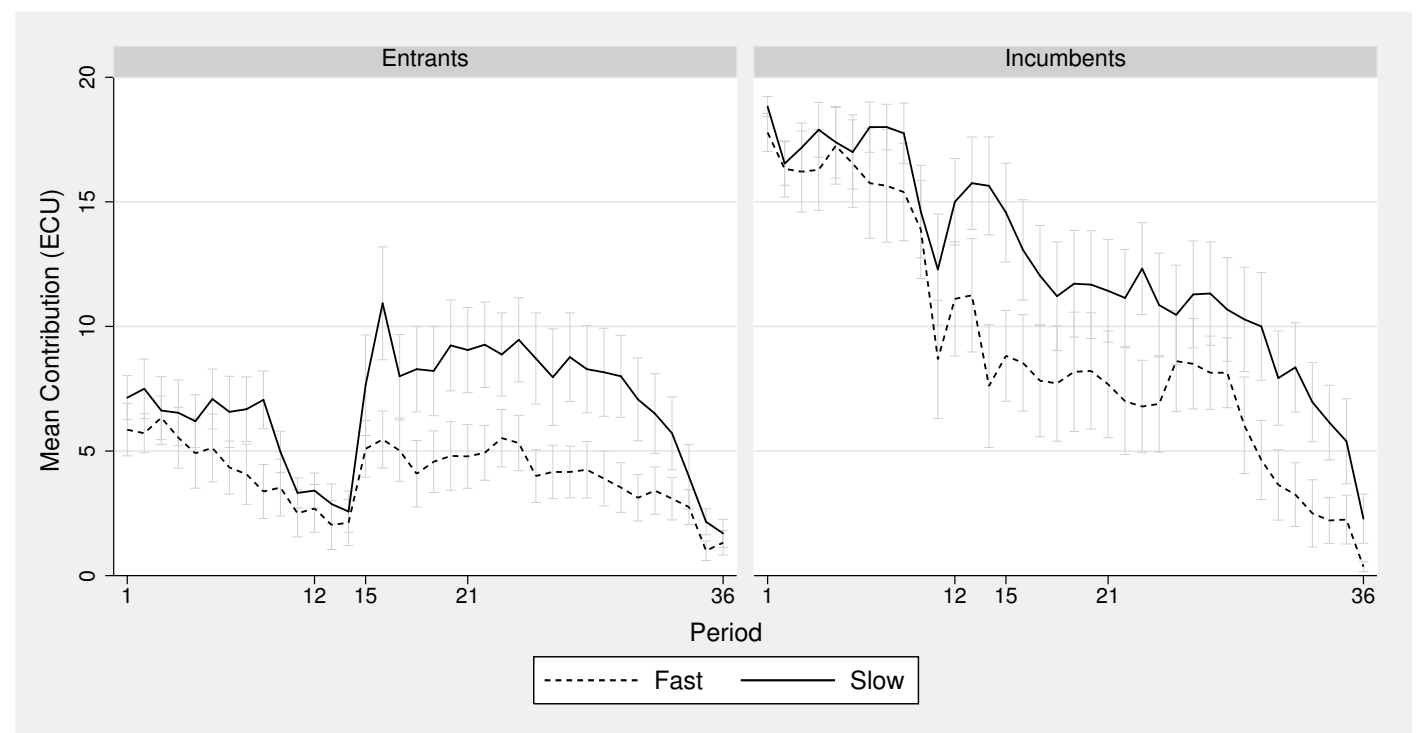

High groups in Phase 2 are 15.9, while in Low groups they are 5.4, and this difference is highly statistically significant when using the group as the unit of observation $\left(t_{54}=9.10\right.$, $p<0.001){ }^{18}$

Despite the use of identical procedures across conditions through Phase 2, Figure 1 shows some differences arising between the Fast and Slow Growth conditions in Phase 2. However, both the differences for High groups (16.7 vs. $\left.15.2, t_{26}=0.76\right)$ and for Low groups (4.5 vs. $\left.6.3, t_{26}=1.33\right)$ fail to reach conventional significance levels. As Table 2 reveals, this lack of statistical significance is also true when considering the first and last five periods of Phase 2 separately. ${ }^{19}$ We thus conclude that our design was successful in creating High groups with greater cooperation, and Low groups with lower cooperation

18. If we consider the Fast and Slow Growth conditions separately, a similar pattern emerges. High groups in the Fast condition contribute, on average, 15.2, while Low groups contribute 4.5. In the Slow condition, the corresponding average contributions are 16.6 and 6.3. In both cases, the differences between High and Low groups are highly statistically significant (Fast: $t_{26}=5.66, p<0.001$; Slow: $\left.t_{26}=7.71, p<0.001\right)$.

19. When making the comparison period-by-period, we again find no statistically significant difference between conditions for any period for High groups $\left(t_{26} \leq 1.11, p>0.27\right.$, for all periods) and a statistically significant difference only for period 7 for the Low groups $\left(t_{26}=2.32, p=0.03 ; t_{26} \leq 1.47, p>0.15\right.$ for all other periods); none of these differences is statistically significant when applying a Bonferroni correction for multiple comparisons. 
levels. In subsequent regression analyses of Phase 3 behavior, we control for any Phase 2 differences.

Table 2: Average Contributions by Condition and Group

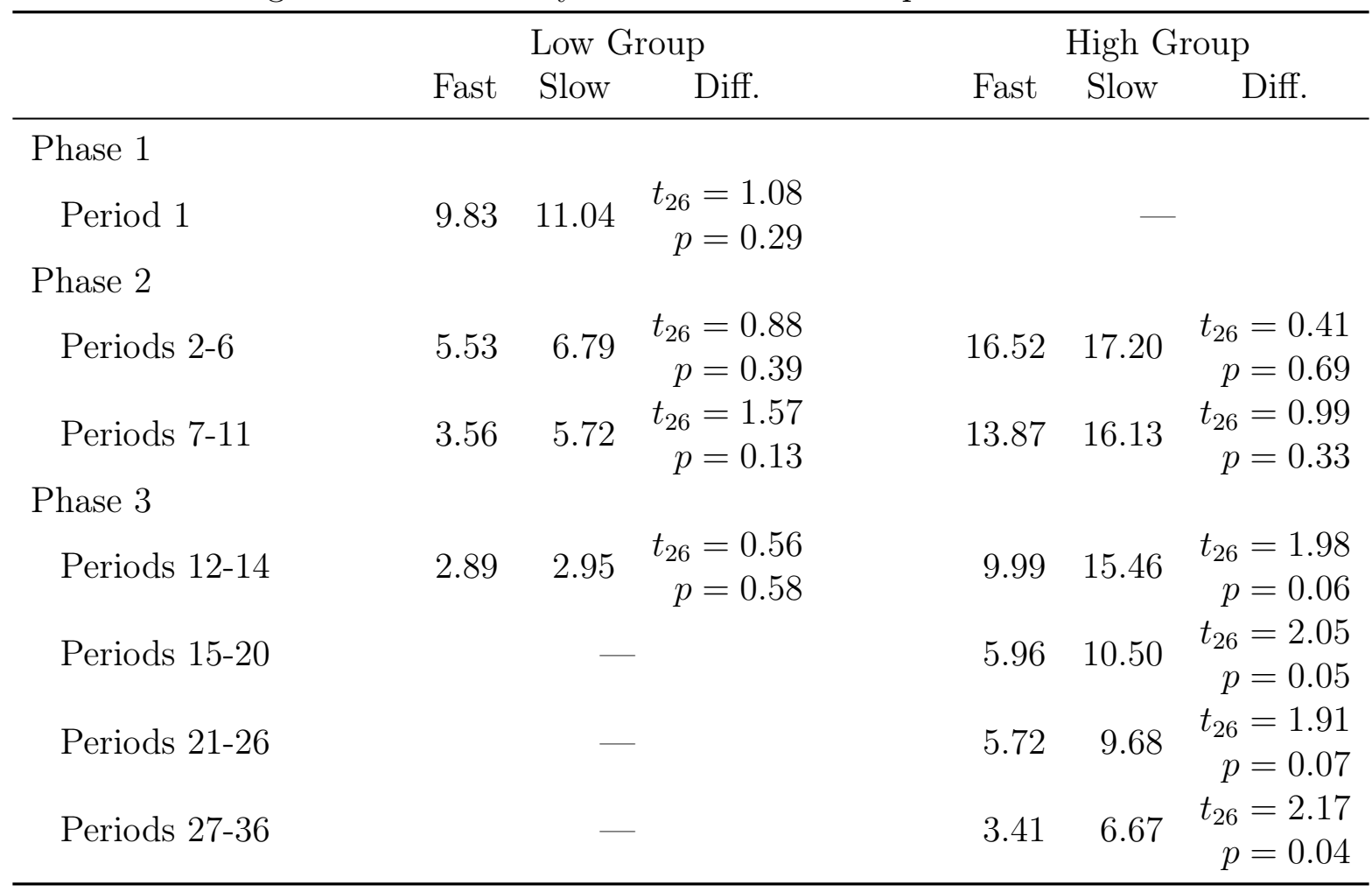

There is no Low vs. High group distinction in Period 1.

\subsection{Is Sustained Cooperation Greater with Slow than Fast Growth?}

In this section we analyze whether, according to our main hypothesis, cooperation rates are higher in the merged six-person groups when this size is attained through Slow, rather than Fast, growth. Returning to Figure 1 and Table 2, we compare average contributions following period 21, once all six participants are in the fully merged matching groups in either condition. Contributions are, on average, approximately 70 percent higher in periods 21-26 of the Slow Growth condition, relative to contributions in the Fast Growth 
condition. ${ }^{20}$ As Table 2 shows, these differences are marginally statistically significant, at $p=0.07$, when using the group as the unit of observation, a conservative analysis. Indeed, in all comparisons in Table 2 following the introduction of the treatment in period 12, average High-group contributions are greater in the Slow growth condition than under Fast growth, by between 54 and 95 percent, and this difference is always at least marginally statistically significant.

\section{Result 1 (Treatment Differences in Merged High Groups)}

As predicted, we observe greater cooperation in High groups in the Slow condition than in the Fast condition, in Phase 3, following the movement of all Low group participants into the High group.

This result is also supported by regression analysis. Table 3 shows the results of randomeffects GLS panel regressions. We include all periods from Phase 2 and periods 12-26 from Phase 3. The unit of observation is a matching group per period and the dependent variable is average contributions. Model 1 considers the behavior of all participants in a six-person matching group, while models 2 and 3 look at the behavior only of incumbents and entrants, respectively. ${ }^{21}$ Binary variables identify the marginal effects of reaching different sets of periods: Period $\geq 12$ (the beginning of Phase 3, after planned movement is announced but not yet implemented), Period $\geq 15$ (when movement is complete in the Fast condition and in progress in the Slow condition), and Period $\geq 21$ (when movement

\footnotetext{
20. Because the rate of entry differs between the two conditions, the High group reaches a size of six sooner in the Fast condition (period 15) than under Slow growth (period 21). Therefore, we might also be interested in comparing contributions between periods 15-20 under Fast growth with those in periods 21-26 under Slow growth, i.e., the first set of periods in which each condition separately achieves full integration. Table 2 reveals that contributions are also higher under Slow growth (9.68) than Fast growth (5.96) and the differences are comparable to those when using periods 21-26.

21. The unit of observation in model 1 is average contributions among all six participants in a matching group in a period; in the two periods in the Slow condition (19-20) in which the one participant remaining in the Low group did not make a choice, we include only the choices by the five active participants. Model 2 uses the average contributions by the two participants originally in the High group. Thus, these two models have 25 periods for 28 groups, or 700 total observations. Model 3 studies the behavior of those originally in the Low group. For the transition periods in the Slow condition (15-18), during which active participants are in both the Low and High groups, the set of observations includes, separately, average contributions among those who are still in the Low group and those who already moved into the High group. This increases the number of observations by 56 ( 4 periods $\times 14$ matching groups).
} 
is complete in both conditions). ${ }^{22}$ The models also include a binary variable identifying the Slow growth condition, and interactions between this variable and the different sets of periods, to identify the marginal effect of reaching a particular block of periods in the Slow growth condition, relative to the Fast growth condition.

We begin with Model 1, which studies the behavior of all six participants in a matching group, and allows a comparison of the behavior in the merged six-person groups. The variable indicating the Slow Growth condition is not statistically significant in Phase 2, periods 2-11. This confirms our earlier analysis showing that there is no substantive difference between the Fast and Slow conditions before the treatment is introduced. Similarly, whereas the variable Period $\geq 12$ indicates that contributions are lower in the first three periods of Phase 3 (the anticipation periods 12-14), than in Phase 2, there is no significant interaction with condition (the variable Slow $\times$ Period $\geq 12$ is insignificant). Thus, until movement from the Low group into the High group begins in Period 15, aggregate contributions in a matching group do not differ significantly by condition. However, as we show below, there are differences for High group incumbents in this "anticipation" phase.

In the Fast growth condition, average contributions increase by about 1.1 ECU for periods 15-20, after growth takes place. This is driven by the increase in contributions exhibited by Low group members moving into the High group (see Figure 1 and analyses below), but counteracted by the decrease in contributions by incumbent High group members. Contributions in the Fast Growth condition fall slightly for periods 21-26, but this decrease is not statistically significant.

The interactions between the period variables and the treatment (Slow Growth) variable allow us to identify the marginal effect of the treatment at different phases of the experiment. Following the introduction of the separate treatment instructions, in period 12, model 1 in Table 3 shows a slight increase in contributions in the Slow condition relative to the Fast condition, but this is not statistically significant, as we noted above. For periods $15-20$, the coefficient is again positive but not statistically significant. This

22. Note that, for example, the cumulative effect of reaching Period 15 is measured by the sum of the two marginal effects, Period $\geq 12$ and Period $\geq 15$. 
is not surprising, as in this interval movement is slowly taking place into the High group in the Slow condition, meaning that there are some original Low group participants who have moved into the High group and others who remain in the Low group.

Our main focus is on what happens after period 21, when the growth process is complete in both conditions. Here, we see an additional positive effect of the interaction between Slow growth and Period $\geq 21$, which is now marginally significant. More importantly, a test of the restriction that the sum of the interaction terms for Period $\geq 12, \operatorname{Period} \geq 15$ and Period $\geq 21$ equals zero is strongly rejected, providing support for Result 2 . That is, relative to a comparison before the introduction of the treatment (before period 12), the net effect of Slow growth by periods 21-26 is positive and highly statistically significant. We can also compare periods 21-26 in the Slow Growth condition with periods $15-20$ in the Fast Growth condition, or the first six periods as a six-person group, by testing the restriction that the coefficients for Slow $\times$ Period $\geq 12+$ Slow $\times$ Period $\geq 15+$ Period $\geq 21+$ Slow $\times$ Period $\geq 21=0$. This restriction is similarly rejected at $p<0.001\left(\chi^{2}(1)=12.83\right)$.

\subsection{Behavior of Incumbents and Entrants in the Fast and the Slow treatment conditions}

We now consider, separately, the behavior of individuals who were originally in the High and Low groups in Phase 2 -i.e., "incumbents" and "entrants," respectively - and how they respond to movement between groups and to the treatment.

\subsubsection{Incumbents}

Returning to Figure 1 and Table 2, a few observations emerge regarding the behavior of incumbents. First, in periods 12-14, we already see a difference in incumbents' con-

\footnotetext{
23. We also ran the same regressions including all 36 periods. The inclusion of these additional periods does not change our results qualitatively: a test of the restriction that the sum of the interaction terms between Slow Growth and Period $\geq 12$, Period $\geq 15$ and Period $\geq 21$ equals zero is still strongly rejected for all models. In comparison to the results presented in Table 3 , the coefficient for the binary Period $\geq 21$ variable is negative and significant, consistent with the end game effect in the final periods.
} 
tributions across conditions. That is, even though growth has not started, we observe an "anticipation effect" after we inform High group participants about the upcoming movement pattern. When comparing periods 12-14 in Table 2, for High groups, we see that this difference is large in magnitude and marginally statistically significant. Thus, even before growth commences, knowledge that growth will be Fast leads High group members to decrease contributions, relative to when they anticipate that growth will be Slow.

In subsequent periods, incumbents in the High group, represented by the right panel in Figure 1, continue to contribute more in the Slow growth condition than with Fast growth. However, the gap is similar to the gap that arises in the anticipation period, suggesting that, for incumbents, this anticipation effect is the main driver of treatment differences in Phase 3 contributions. That is, knowing that Fast growth will occur leads High group incumbents to lower their contributions, relative to when they know Slow growth is coming, and this difference in contributions by incumbents then persists throughout the growth process.

\section{Result 2 (Treatment Differences in Incumbent Behavior)}

Incumbent High group members contribute more in Phase 3 under Slow growth than Fast growth. Most of this difference arises already in the anticipation period, after participants are informed about upcoming growth, but before it commences.

This result is also apparent in model 2 of Table 3, which analyzes only the average contributions by the two High group incumbents. As before, the unit of observation is a matching group in a period. The interaction term for Period $\geq 12$ is positive, large in magnitude, and statistically significant, indicating that, on average, High group members contribute roughly 4 ECU more in this anticipation period in the Slow growth condition than in the Fast growth condition. The statistically insignificant interaction terms for all subsequent periods indicate that this difference is fairly stable over time. A test of the restriction that the sum of the three interaction terms equals zero is rejected at $p=0.03$, indicating that the statistically significant higher contributions of incumbents in the Slow growth condition persist into periods 21-26. 
Table 3: Random effects GLS panel regression. Dependent variable average contributions. Unit of observation Group-Period

\begin{tabular}{|c|c|c|c|}
\hline & $\begin{array}{c}(1) \\
\text { All subjects }\end{array}$ & $\begin{array}{c}(2) \\
\text { Incumbents }\end{array}$ & $\begin{array}{c}(3) \\
\text { Entrants }\end{array}$ \\
\hline Slow Growth & $\begin{array}{r}1.629 \\
(1.391)\end{array}$ & $\begin{array}{r}1.468 \\
(2.092)\end{array}$ & $\begin{array}{r}1.709 \\
(1.381)\end{array}$ \\
\hline Period $\geq 12$ & $\begin{array}{l}-3.242^{* * *} \\
(0.525)\end{array}$ & $\begin{array}{l}-5.208^{* * *} \\
(0.863)\end{array}$ & $\begin{array}{l}-2.259^{* * *} \\
(0.617)\end{array}$ \\
\hline Slow $\times$ Period $\geq 12$ (a) & $\begin{array}{r}0.641 \\
(0.742)\end{array}$ & $\begin{array}{l}4.008^{* * *} \\
(1.220)\end{array}$ & $\begin{array}{l}-1.042 \\
(0.873)\end{array}$ \\
\hline Period $\geq 15$ & $\begin{array}{l}1.111^{* *} \\
(0.564)\end{array}$ & $\begin{array}{c}-1.774^{*} \\
(0.927)\end{array}$ & $\begin{array}{l}2.554^{* * *} \\
(0.663)\end{array}$ \\
\hline Slow $\times$ Period $\geq 15(b)$ & $\begin{array}{r}0.509 \\
(0.798)\end{array}$ & $\begin{array}{r}-1.310 \\
(1.311)\end{array}$ & $\begin{array}{r}-1.009 \\
(0.976)\end{array}$ \\
\hline Period $\geq 21$ & $\begin{array}{r}-0.248 \\
(0.460)\end{array}$ & $\begin{array}{r}-0.637 \\
(0.757)\end{array}$ & $\begin{array}{r}-0.054 \\
(0.541)\end{array}$ \\
\hline Slow $\times$ Period $\geq 21(\mathrm{~d})$ & $\begin{array}{c}1.181^{*} \\
(0.651)\end{array}$ & $\begin{array}{r}-0.494 \\
(1.070)\end{array}$ & $\begin{array}{r}0.225 \\
(0.766)\end{array}$ \\
\hline Slow $\times$ Period $\geq 15 \times \operatorname{High}(\mathrm{c})$ & & & $\begin{array}{l}4.221^{* * *} \\
(0.605)\end{array}$ \\
\hline Constant & $\begin{array}{l}8.095^{* * *} \\
(0.984)\end{array}$ & $\begin{array}{l}15.196^{* * *} \\
(1.479)\end{array}$ & $\begin{array}{l}4.545^{* * *} \\
(0.976)\end{array}$ \\
\hline $\begin{array}{l}\text { Cumul. treat. effect, Period } \geq 21 \\
(\mathrm{a})+(\mathrm{b})+(\mathrm{c})+(\mathrm{d})=0\end{array}$ & $\begin{array}{c}\chi^{2}(1)=16.03 \\
p<0.001\end{array}$ & $\begin{array}{c}\chi^{2}(1)=5.30 \\
p=0.03\end{array}$ & $\begin{array}{c}\chi^{2}(1)=12.24 \\
p<0.001\end{array}$ \\
\hline $\mathrm{N}$ & 700 & 700 & 756 \\
\hline
\end{tabular}

* $\mathrm{p}<0.10,{ }^{* *} \mathrm{p}<0.05,{ }^{* * *} \mathrm{p}<0.01$

The individuals who remain alone in the Low group in periods 19 and 20 are omitted since they do not make an active decision in these two periods.

\subsubsection{Entrants}

We also observe a treatment effect on the behavior of entrants. On average, entrants in the Slow growth condition contribute more than entrants in the Fast condition. Average contributions by entrants in periods 21-26 are almost twice as high in the Slow condition (8.89) as in the Fast condition (4.79).

\section{Result 3 (Treatment Differences in Entrant Behavior)}

Entrants into the High group from the Low group increase their contributions more in the Slow growth condition than in the Fast growth condition; the increase occurs after 
entry into the High group.

This result is also supported by model 3 in Table 3, which studies the average contributions by entrants, i.e., those participants who started in the Low group in Phase 2 , and eventually moved into the High group. The negative coefficient for Period $\geq 12$ shows that contributions for Low group members decrease significantly in periods 12-14, relative to Phase 2, but there is no significant difference between the conditions. In the Fast Growth condition, average contributions increase by about 2.5 for Period $\geq 15$ and then remain flat.

The behavior of entrants in the Slow condition during periods 15 to 20 is identified by two variables. First, the interaction between Slow and Period $\geq 15$ shows that entrants in the Slow condition who are still in the Low group contribute slightly less than do entrants in the Fast condition who have already entered the High group. The next interaction term (Slow $\times$ Period $\geq 15 \times$ High) shows that, once these participants make the move from the Low group into the High group, their contributions increase by about 4.2 ECU, on average. Finally, we can identify the cumulative effect of a Low group participant being in the Slow growth condition, on contributions in periods 21-26, by summing the interaction terms. This reveals the treatment effect to be highly statistically significant $(p<0.001)$.

\subsection{Earnings}

If we compare earnings from Period 21 onwards, when in each condition there are fully merged six-person groups, the reunited groups in the Slow condition earn more, on average, than those in the Fast condition. In periods 21 to 26, participants in the Fast condition earn, on average, 25.7 ECU and participants in the Slow condition earn 29.7 ECU. Using average earnings in the matching group as the unit of observation, this difference is marginally statistically significant $\left(t_{26}=1.91, p=0.07\right)$.

Average profits at the matching group level, however, potentially obscure differences in earnings between incumbents and entrants. We saw that entrants' contributions are persistently lower than those of the incumbents, i.e., they free-ride on the incumbents' contributions. The result is that they enjoy, on average, higher profits, as can be seen 
in Figure 2. In both treatment conditions, entrants earn more after moving to the High group than do incumbents. ${ }^{24}$ But, both incumbents and entrants earn more in the Slow growth condition than under Fast growth. ${ }^{25}$

Importantly, both kinds of participants in the Slow condition also fare better in the merged group than in Phase 2, when they played the game separately in smaller Low and High groups. In the Slow growth condition, incumbents' average earnings rise from 25.2 ECU in Phase 2 (periods 2-11) to 28.1 ECU in periods 21-26. But, this is not true in the Fast growth condition, where incumbent High group members obtained slightly higher average earnings in Phase 2, before growth (mean earnings $=24.7$ ECU), than in periods 15-20 (23.7 ECU) or in periods 21-26 (mean earnings = 23.9 ECU). Thus, while entry is always profitable for the entrants, it is only profitable for incumbents if growth occurs slowly.

\section{Result 4 (Earnings Differences between Fast and Slow Growth)}

Earnings in merged six-person groups are higher after Slow growth than after Fast growth. In the Slow growth condition, both entrants' and incumbents' earnings increase relative to Phase 2. In the Fast growth condition, entrants' earnings increase, but incumbents' earnings decrease slightly relative to Phase 2.

This result raises the question of what kinds of growth paths arise when they are endogenously determined by High group members.

\subsection{Growth, contributions and profits in the Voting condition}

As we show above in the comparison between the Fast and the Slow conditions, the rate of entry has important implications for cooperation in grown groups. Cooperation and earnings are higher under Slow growth than with Fast growth. Moreover, the growth process leaves High-group incumbents better off in the Slow growth condition, but slightly

24. In particular, in the Slow growth condition, entrants earn, on average, 30.5 ECU in periods 21-26, while incumbents earn 28.1 ECU; in the Fast growth condition, entrants earn on average 26.6 ECU, while incumbents earn 23.9 ECU.

25. For incumbents, the difference of 28.1 vs. 23.9 is significant $\left(t_{26}=2.12, p=0.04\right)$. For entrants, the difference of 30.5 vs. 26.6 is marginally significant $\left(t_{26}=1.69, p=0.10\right)$. 
Figure 2: Average earnings over time, incumbents and entrants. Bars represent standard errors. Unit of observation $=$ matching group.

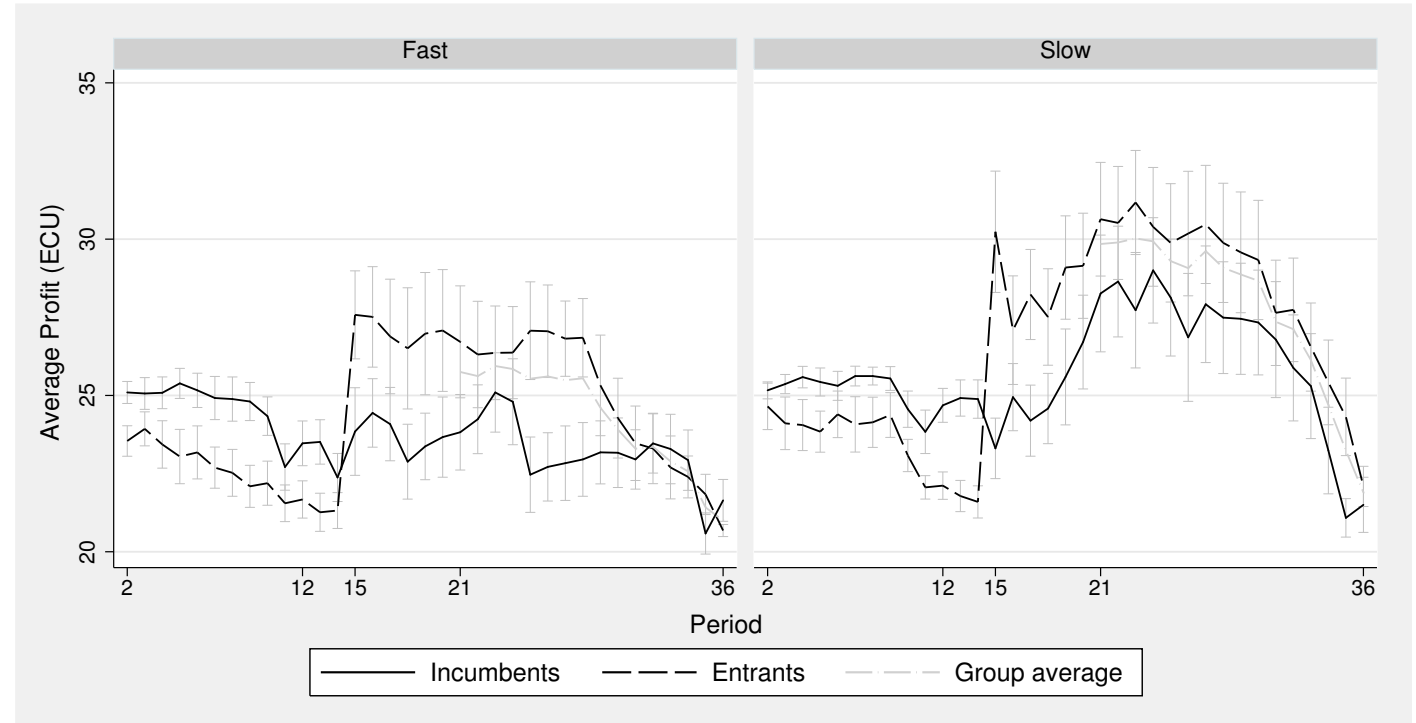

worse off following Fast growth. Therefore, we next ask whether groups in the Voting condition - where growth trajectories are determined endogenously by members of the High group - employ growth trajectories similar to those in our Fast growth or Slow growth conditions, or something altogether different. We then consider cooperation and earnings in the Voting condition.

Figure 3(a) shows the average growth trajectory in the Voting condition, and compares it with the exogenously imposed growth trajectories in the Fast and Slow growth conditions. At the onset of voting, in periods 15 and 16, groups in the Voting condition grow at a similar rate to groups in the Slow growth condition. They add, on average, 1.3 entrants in these periods, which is slightly higher than the single entrant added through Slow growth. Thus, when High groups can decide on a growth rate, they forgo Fast growth - which would involve adding all four entrants at once - in favor of a growth trajectory that is initially similar to the one in our Slow growth condition.

But the average growth rate then decreases, even relative to our Slow growth condition, and the average group size by period 21 , when the possibility of growth ends, is 4.3 . Thus, on average, groups in the Voting condition allow entry to only about half of the original 
Low group members.

Figure 3: Voting: average growth rate and final group size

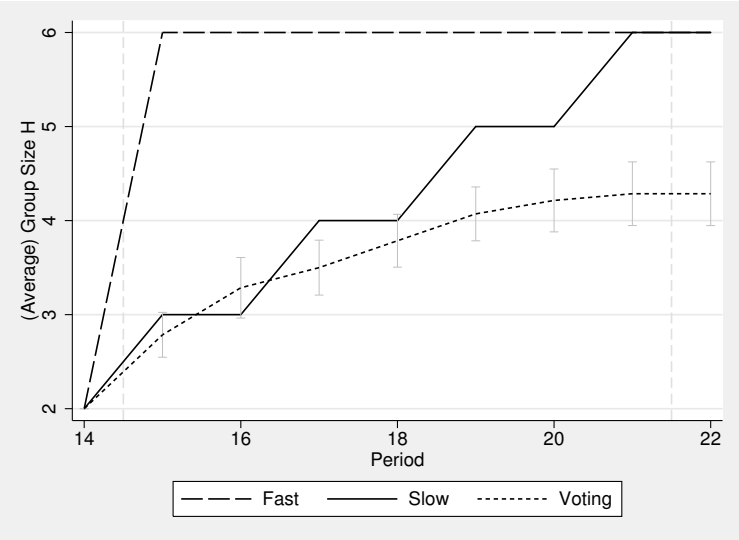

(a) Average growth rate

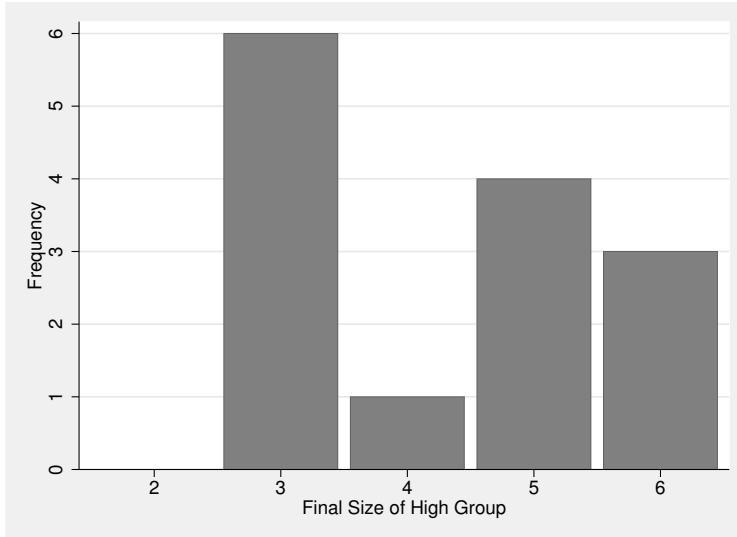

(b) Final group size

Of course, Figure 3(a) conceals heterogeneity in growth between groups. To uncover this heterogeneity, Figure 3(b) reports the distribution of final group sizes attained by groups in the Voting condition. Entry into the High groups always occurs - no group ends up at a size of two - but the modal group integrates only one new member, growing only to a size of three. Only three out of the fourteen groups in this condition reach the maximum size of six.

\section{Result 5 (Growth in the Voting Condition)}

When High group members vote on entry, growth paths are initially similar to those in the Slow growth condition, but growth slows down subsequently. The resulting groups rarely achieve full integration.

Voting behavior produces groups that fall short of full integration. This means that they fail to realize greater potential profits from the economies of scale provided by the return to public good contributions, $m$, which increases with group size. Of course, whether larger group sizes yield higher profits depends also on contributions, so we next explore the relationship between group size, contributions and earnings.

The reluctance to grow occurs despite relatively high average contributions in the voting condition compared to the other conditions. Average contributions in periods 21 
to 26 in the Voting condition (10.6 ECU) are slightly higher than those in the Slow growth condition (9.7 ECU), as shown in Figure 4(a). Both of these conditions obtain higher mean High-group contributions than the High groups in the Fast growth condition (5.7 ECU). Thus, when it comes to sustaining high rates of voluntary cooperation, High groups in the Voting condition do better than groups in the condition with exogenous Fast growth. ${ }^{26}$

However, the second panel of the figure also reveals that average contributions vary substantially with the final group size. In groups that end up at a size of 3, average contributions are quite high (15.4 ECU, or 77 percent of the endowment), while for groups that grow to a size of 6 they are 2.8 ECU. Thus, we find a strong relationship between the growth process and final contributions.

Looking more closely at the data, it appears that at least part of the causality for the relationship in Figure 4(b) lies with differential High group contributions in Phase 2, which then drive the subsequent endogenous growth in Phase 3. In particular, the High groups that ultimately stopped growing at a group size of 3 had higher average contributions in periods $7-11$ of Phase 2 (14.7 ECU), with five of the six such groups having average contributions of at least 10 ECU. On the other hand, the three groups that grew to a size of six had considerably lower average contributions in the second half of Phase 2 (5.5 ECU) and none of these groups had mean contributions above $9 .^{27}$

\section{Result 6 (Contributions in the Voting Condition)}

On average, High-group contribution levels are similar in the Voting condition to those in the Slow Growth condition, and both are higher than under Fast Growth. Contribution levels differ considerably by final group size, with smaller groups obtaining much higher

26. Using the group as the unit of observation, period 21-26 average contributions are higher in the Voting condition than under Fast growth $\left(t_{26}=2.13, p=0.04\right)$.

27. Separate regression analyses confirm that final group size depends on High-group contributions in Phase 2, and that incumbent contributions in Phase 2 also predict High-group contributions in Periods 21-26. Including both average High-group contributions in Periods 7-11 and final group size in a regression of post-growth contributions shows that the effect of final group size is partly driven by early High-group contributions: while the final group-size effect remains large and significant, adding Phase-2 contributions decreases the effect by 24 percent, confirming that groups that do not grow much are the ones who tended to cooperate more in Phase 2, and that this partly explains why they also obtain higher contributions after Period 21. 
contribution levels. High groups with high Phase 2 contributions tend to grow less and maintain higher contributions than groups with low contributions in Phase 2.

Figure 4: Average contributions in High group by condition and final group size

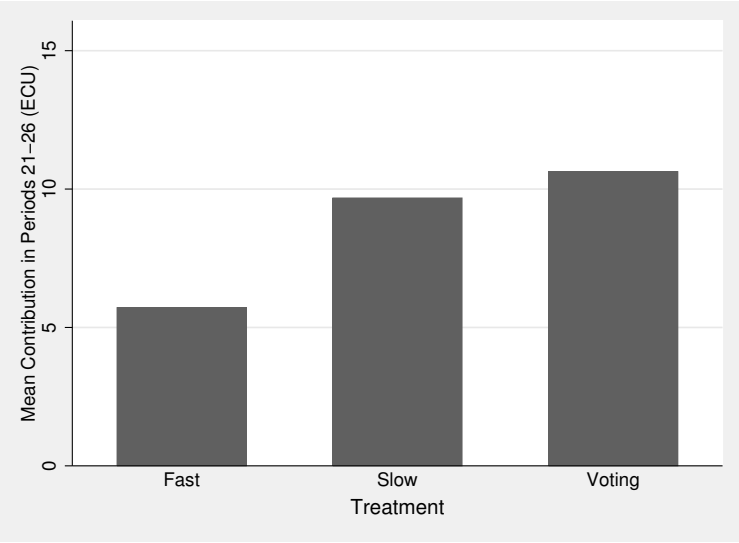

(a) Contributions in High group by Condition

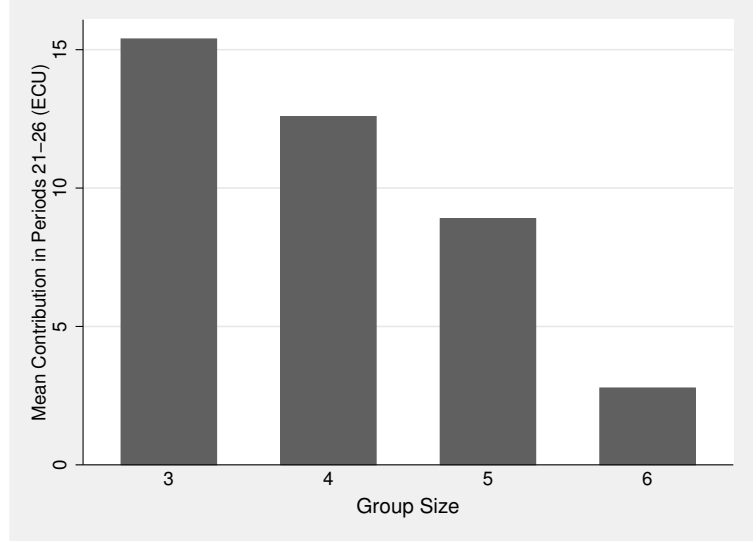

(b) Voting: Contributions in High group by Final Group Size

Despite the high levels of contributions in the Voting condition, however, average earnings are close to those in the Fast growth condition (see Figure 5). This follows from our earlier observation, in Figure 4(b), that High groups in the Voting condition are either successful (they obtain high contributions) or large, but not both, which stands in remarkable contrast to the Slow growth condition, where we tended to obtain successful large groups. In the Voting condition, groups that attain final sizes from 3 to 5 produce average earnings for their members of between 27.0 and $27.8 \mathrm{ECU}$, which is relatively close to the mean earnings in the Slow condition (29.7). However, earnings are substantially lower for groups that endogenously grow to a size of 6 (22.8 ECU).

So, why do groups in the Voting condition stop growing? We study voting behavior using regression analysis, which we report in Table 4 . The dependent variable in these regressions is a binary variable taking the value of 1 if a participant voted for any positive number of entrants in the current period, and 0 otherwise. ${ }^{28}$ In a first specification we include variables pertaining to the game history, such as lagged average contributions

28. The reported regressions are OLS. Probit regressions yield qualitatively similar results. 
in the High and the Low group, the change in average contributions in the High group from two periods ago to the last period, an indicator for whether growth occurred in the previous period, and the interaction between these last two variables. This interaction identifies any sensitivity to what happened to average contributions the last time the group grew. Interestingly, none of these variables are significant predictors of the decision to vote for growth, indicating that what happened previously-including whether the group grew in the last period-has limited value in predicting voting behavior.

In the second model we look at individual participant characteristics, such as gender, age, socioeconomic background, Swiss nationality and political orientation. We also introduce whether the participant is an incumbent or an entrant into the High group, and how much the individual contributed in the first period of the experiment (Phase 1). We find that two individual characteristics predict votes for growth. Women are 38 percentage points more likely to vote for entry by a newcomer than are men, while participants who report higher parental educational attainment are 18 percentage points more likely to vote for growth. Further, prior entrants - i.e., those who previously moved from the Low group into the High group - are 35 percentage points less likely to vote for entry than are incumbents. ${ }^{29}$ Note that we find this result while controlling for Phase 1 contributions, indicating that it is not just the case that less cooperative types vote against growth.

Model 3 incorporates those predictors from model 2 that are statistically significant, or marginally significant, into the regression in model 1 . We see that whether a participant is an entrant or female, and the level of parental education, have similar effects to those in model 2. However, the inclusion of these variables also now makes average lagged High group contributions significant-implying that individuals in High groups that are performing better tend to be more reluctant to grow, by roughly one percentage point per average unit increase in contributions. ${ }^{30}$

29. To control for repeated observations within groups, and a small number of independent groups (14), we report bootstrapped standard errors. We also ran the same regressions using the wild bootstrap, as proposed by Cameron, Gelbach, and Miller (2008). Qualitatively, the results are similar to the ones presented above. Making use of additional survey data we also controlled for the amount of CHF a subject donates to charity per year, as well as measures of propensity to engage in risky and trusting behavior (based on hypothetical questions). These variables add little predictive power to the model.

30. This is consistent with our earlier finding that successful High groups are less likely to grow. If we 
This regression analysis identifies a couple of factors that contribute to the stalled growth among many successful groups in the Voting conditions. One reason is that early entrants vote against additional growth. Aggregating across periods, we see that incumbents vote for growth 41 percent of the time, while entrants vote to allow additional entry into the group only 16 percent of the time. A second reason is that individuals in cooperative High groups are less likely to vote for additional growth. Together, these two patterns provide a partial interpretation of the earlier observation that many successful groups add one or two entrants and then stop growing. Specifically, groups that are doing well are less likely to vote for more growth and such groups become even less likely to grow after adding one entrant.

\section{Result 7 (Voting Behavior)}

Entrants into the High group are significantly less likely to vote for additional growth than incumbents. Women and participants with higher parental education are more likely to vote for growth. Members of more cooperative High groups are less likely to vote for growth.

\subsection{Welfare in the different treatment conditions}

Finally, we consider mean earnings across the three conditions. This provides us with a comparison of how well the three distinct growth processes fared in producing large, fully integrated High groups with high voluntary contribution levels.

Figure 5 graphs mean earnings in the High and Low groups, by condition. Consistent with our central hypothesis, High group earnings are higher in the Slow growth condition relative to the Fast growth condition after period 21, when the growth phase is completed in all treatment conditions. However, average welfare in the Voting condition, when growth is endogenously determined, is comparable to the welfare generated by the Fast condition, and significantly lower than the resulting welfare arising in the Slow condition.

additionally control for Phase 2 contributions in the High group, the results are qualitatively similar, though the effect of lagged High group contributions is slightly weaker in statistical significance. This is likely due to both variables similarly measuring the history of successful cooperation in the High group. 
Figure 5: Average profits in the three conditions

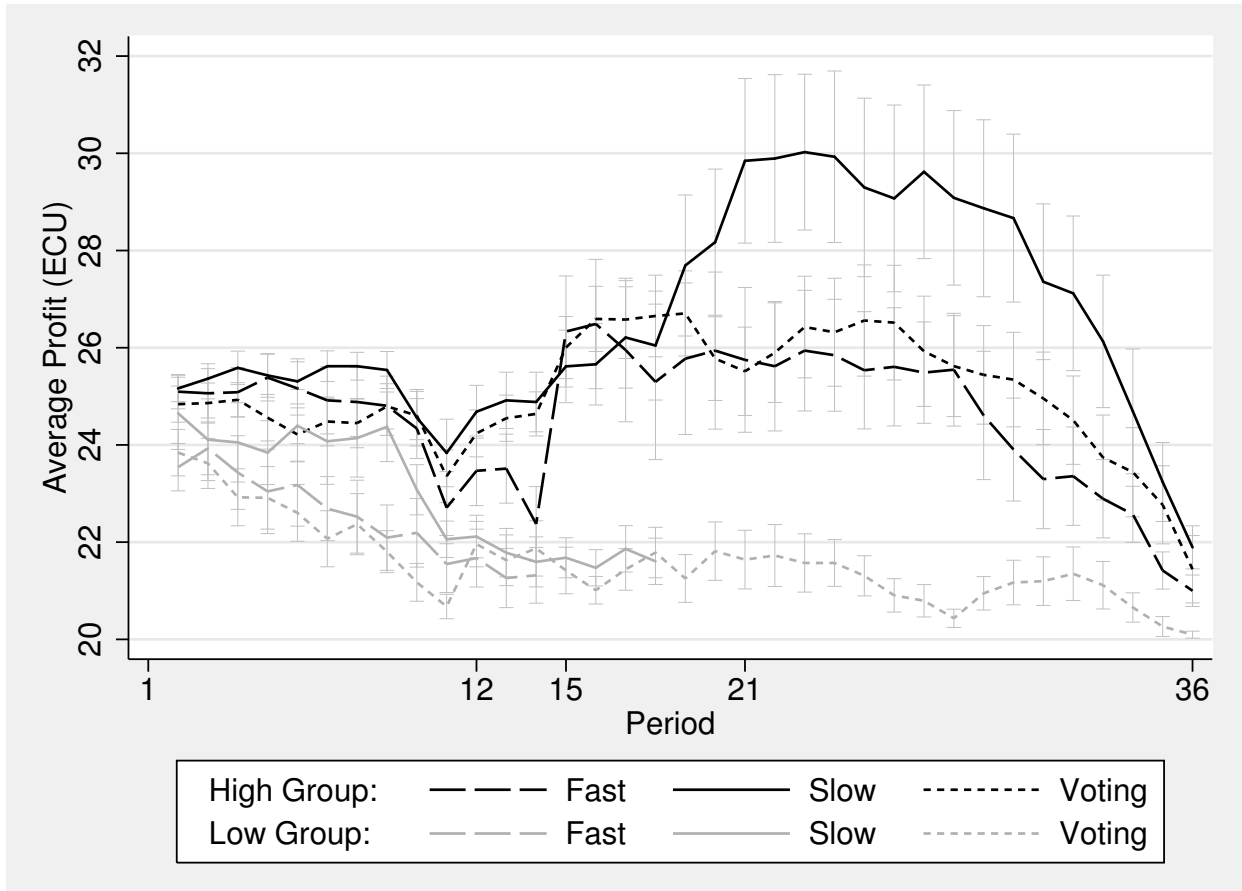

Thus, our final result suggests that growth trajectories endogenously determined by group members may be too conservative, and may therefore leave unrealized potential profits due to further slow growth.

\section{Result 8 (Earnings in the Voting Condition)}

Slow growth produces a high average welfare, while the Fast growth condition and the Voting condition result in comparable levels of welfare, which are both significantly lower than in the Slow condition.

\section{Conclusion}

We study how a group with an established norm of high cooperation can sustain cooperative behavior as it grows, and particularly as it incorporates individuals without a history of acting cooperatively. Our focus is on the speed at which a group grows. While other mechanisms than the rate of entry - such as screening, monitoring and incentives - can facilitate cooperation in growing groups, such instruments are not always available, as 
individual cooperative behavior is often difficult to observe directly. Thus, growing more slowly may present one mechanism through which a group can facilitate sustaining high levels of cooperation.

Our findings support the idea that slow growth facilitates the persistence of cooperative norms. Specifically, in comparing an experimental condition in which a group grows slowly with one in which growth occurs rapidly, we find cooperation to be significantly higher in the former. This is due both to more persistently high levels of cooperation by incumbents in the high-performing group that receives entrants, and to the behavior of entrants, who increase cooperation to a greater extent when entering slowly, i.e., one by one, rather than all at once.

These results qualitatively confirm those of a simple simulation-based exercise, in which we started from a leading belief-based model of behavior in repeated public good games, and modified it slightly to accommodate our research design. In this simple exercise, we find that cooperation in the integrated group is higher when growth occurs slowly rather than quickly, and particularly for parameter configurations that place significant emphasis on beliefs. This indicates that our results are likely more general than the particular case of our experiment, though of course the open question of precisely when and where slowly grown groups will obtain higher cooperation than groups that grow more rapidly requires further research.

We also find that giving the people the right to decide how quickly to grow groups yields mixed success. While such groups generally obtain high cooperation rates, they fail to grow to the large sizes that would allow them to fully realize the economies of scale in public good provision that we endow to larger group sizes. Thus, the modal group in our condition with voting grows only slightly, but maintains high degrees of voluntary cooperation. We also find that this can be interpreted as caution in groups that possess high cooperation rates, and particularly caution among new entrants, who tend to exhibit much more opposition to further growth than incumbents. ${ }^{31}$

31. This is consistent with circumstantial evidence of naturalized or second-generation immigrants voting for right-wing anti-immigration policies. For example, during the French presidential election campaign of 2012, stories about naturalized citizens of Arab origin made the news because they identified themselves as voters of the ultra-nationalist "Front National", a strongly anti-immigration party (Kerkoud 
Our results are relevant for situations in which the conflict between private incentives and collective benefits are important, and in which a group whose members confront such conflict attempts to grow. In such situations, and particularly when it is difficult to directly incentivize cooperative behavior or use past individual behavior as a means of excluding individuals from the growing group, it is important to identify mechanisms that facilitate sustaining voluntary cooperation throughout the growth process. We find that an exogenously imposed slow rate of growth presents such a mechanism, and one that is widely applicable whenever there is discretion over the rate at which a group grows.

It is also important to note that our results do not suggest that slow growth is always better. Our experiment is just one stylized representation of many analogous situations outside the laboratory, in growing firms, social groups, and communities. ${ }^{32}$ As with any laboratory experiment, the similarities should be viewed cautiously. For example, in many real world situations, movement from low-cooperation environments endows individuals who are able to move with far greater gains than are captured by our design. Thus, when conditions in the low-cooperation environments are unpalatable, it may be socially efficient to grow quickly, even if this has a detrimental effect on cooperation in the group receiving entrants. But, we present our results as evidence that - in most such situationsthe rate of growth at least merits attention as a potentially important factor influencing outcomes.

2013).

32. Indeed, all of our design choices mean that one should be careful in generalizing our results to other settings, with perhaps different production technologies, growth trajectories, and relative cooperativeness of incumbent group members and entrants. However, in order to study whether the rate of growth impacts the sustainability of voluntary cooperation, one must start somewhere, and our design is in many ways a natural starting point. 
Table 4: OLS regression, dependent variable: vote for entry $(=1)$ or against $(=0)$. Standard errors are bootstrapped.

\begin{tabular}{|c|c|c|c|}
\hline & M1 & M2 & M3 \\
\hline avg. Contr. High (t-1) & $\begin{array}{c}-0.009 \\
(0.006)\end{array}$ & & $\begin{array}{l}-0.012^{* *} \\
(0.005)\end{array}$ \\
\hline avg. Contr. Low (t-1) & $\begin{array}{c}-0.003 \\
(0.009)\end{array}$ & & $\begin{array}{r}-0.003 \\
(0.009)\end{array}$ \\
\hline Change in Contr. High (t-2 to t-1) & $\begin{array}{r}0.002 \\
(0.019)\end{array}$ & & $\begin{array}{r}0.008 \\
(0.016)\end{array}$ \\
\hline Group Growth (t-2 to t- 1$)$ & $\begin{array}{r}0.075 \\
(0.064)\end{array}$ & & $\begin{array}{r}0.065 \\
(0.055)\end{array}$ \\
\hline Growth x Contr. & $\begin{array}{r}0.024 \\
(0.021)\end{array}$ & & $\begin{array}{r}0.010 \\
(0.018)\end{array}$ \\
\hline Contribution Period 1 & & $\begin{array}{r}-0.003 \\
(0.007)\end{array}$ & \\
\hline Entrant & & $\begin{array}{l}-0.345^{* * *} \\
(0.121)\end{array}$ & $\begin{array}{l}-0.310^{* * *} \\
(0.082)\end{array}$ \\
\hline Female & & $\begin{array}{l}0.375^{* * *} \\
(0.093)\end{array}$ & $\begin{array}{l}0.304^{* * *} \\
(0.078)\end{array}$ \\
\hline Age & & $\begin{array}{r}0.012 \\
(0.023)\end{array}$ & \\
\hline Disposable Income Parents & & $\begin{array}{r}0.026 \\
(0.113)\end{array}$ & \\
\hline Parental Education & & $\begin{array}{c}0.179^{* *} \\
(0.072)\end{array}$ & $\begin{array}{l}0.185^{* * *} \\
(0.057)\end{array}$ \\
\hline Swiss Nationality & & $\begin{array}{r}-0.020 \\
(0.078)\end{array}$ & \\
\hline Polit. Orientation $(0=$ far left, $9=$ far right $)$ & & $\begin{array}{r}0.037 \\
(0.023)\end{array}$ & \\
\hline Constant & $\begin{array}{c}0.440^{* * * *} \\
(0.085)\end{array}$ & $\begin{array}{r}-0.168 \\
(0.592) \\
\end{array}$ & $\begin{array}{c}0.387^{* * *} \\
(0.106)\end{array}$ \\
\hline $\begin{array}{l}\text { R-squared } \\
\mathrm{N}\end{array}$ & $\begin{array}{r}0.008 \\
289\end{array}$ & $\begin{array}{r}0.198 \\
289\end{array}$ & $\begin{array}{r}0.198 \\
289\end{array}$ \\
\hline
\end{tabular}




\section{References}

Ahn, T. K., R. Mark Isaac, and Timothy C. Salmon. 2008. "Endogenous Group Formation." Journal of Public Economic Theory 10 (2): 171-194.

Ahn, T.K., E. Ostrom, D. Schmidt, R. Shupp, and J. Walker. 2001. "Cooperation in PD games: Fear, greed, and history of play." Public Choice 106 (1): 137-155.

Aimone, Jason A., Laurence R. Iannaccone, Michael D. Makowsky, and Jared Rubin. 2013. "Endogenous Group Formation via Unproductive Costs*." The Review of Economic Studies.

Ambrus, Attila, and Parag A. Pathak. 2011. "Cooperation over finite horizons: A theory and experiments." Journal of Public Economics 95 (7-8): 500-512.

Cain, M. 1998. "An experimental investigation of motives and information in the prisoner's dilemma game." Advances in Group Processes 15:133-160.

Cameron, A. Colin, Jonah B. Gelbach, and Douglas L. Miller. 2008. "Bootstrap-Based Improvements for Inference with Clustered Errors." Review of Economics and Statistics 90 (3): 414-427.

Chamberlin, John. 1974. "Provision of Collective Goods as a Function of Group Size." American Political Science Review 68 (2): 707-716.

Charness, Gary. 2000. "Bargaining efficiency and screening: an experimental investigation." Journal of Economic Behavior \& Organization 42 (3): 285-304.

Charness, Gary, and Chun-Lei Yang. 2008. Endogenous Group Formation and Public Goods Provision: Exclusion, Exit, Mergers, and Redemption. Economics Working Paper Series, No. qt0hx472pn. University of California at Santa Barbara.

Chaudhuri, Ananish, Sara Graziano, and Pushkar Maitra. 2006. "Social learning and norms in a public goods experiment with inter-generational advice." The Review of Economic Studies 73 (2): 357-380.

Dur, Robert, and Joeri Sol. 2010. "Social interaction, co-worker altruism, and incentives." Games and Economic Behavior 69 (2): 293-301. 
Esteban, Joan, and Debraj Ray. 2001. "Collective Action and the Group Size Paradox." American Political Science Review 95 (03): 663-672.

Fehr, Ernst, and Simon Gächter. 2000. "Cooperation and Punishment in Public Goods Experiments." American Economic Review 90 (4): 980-994.

Fischbacher, Urs. 2007. "z-Tree: Zurich toolbox for ready-made economic experiments." Experimental Economics 10 (2): 171-178.

Fischbacher, Urs, and Simon Gächter. 2010. "Social Preferences, Beliefs, and the Dynamics of Free Riding in Public Goods Experiments." American Economic Review 100 (1): $541-556$.

Fischbacher, Urs, Simon Gächter, and Ernst Fehr. 2001. "Are people conditionally cooperative? Evidence from a public goods experiment." Economics Letters 71 (3): $397-404$.

Gächter, Simon, and Christian Thöni. 2005. "Social Learning and Voluntary Cooperation among Like-Minded People." Journal of the European Economic Association 3 (2-3): 303-314.

Greiner, Ben. 2004. "The Online Recruitment System ORSEE - A Guide for the Organization of Experimens in Economics." In Forschung und wissenschaftliches Rechnen, edited by Kurt Kremer and Volker Macho, 79-94. GWDG-Berichte 63. Göttingen: Gesellschaft für wissenschaftliche Datenverarbeitung.

Gürerk, Özgür, Bernd Irlenbusch, and Bettina Rockenbach. 2006. "The Competitive Advantage of Sanctioning Institutions." Science 312 (5770): 108-111.

Hamman, John R, Roberto A Weber, and Jonathan Woon. 2011. "An experimental investigation of electoral delegation and the provision of public goods." American Journal of Political Science 55 (4): 738-752.

Isaac, R. Mark, and James M. Walker. 1988. "Group Size Effects in Public Goods Provision: The Voluntary Contributions Mechanism." Quarterly Journal of Economics 103 (1): 179-199. 
Isaac, R. Mark, James M. Walker, and Arlington W. Williams. 1994. "Group size and the voluntary provision of public goods: Experimental evidence utilizing large groups." Journal of Public Economics 54 (1): 1-36.

Kerkoud, Malika. 2013. 'I'm Arab, a Muslim, and I vote Marine Le Pen'. France 24.

Kosfeld, Michael, Akira Okada, and Arno Riedl. 2009. "Institution formation in public goods games." The American Economic Review:1335-1355.

Ledyard, John O. 1995. "Public Goods: A Survey of Experimental Research." In Handbook of Experimental Economics, edited by John H. Kagel and Alvin E. Roth, 111-194. Princeton, New Jersey: Princeton University Press.

Mauro, Paolo. 1995. "Corruption and Growth." Quarterly Journal of Economics 110 (3): $681-712$.

Olson, Mancur. 1971. The logic of collective action public goods and the theory of groups. [1st ed. 1965] 2nd print. Harvard economic studies, Vol. 124. Cambridge, Massachusetts: Harvard University Press.

Page, Talbot, Louis Putterman, and Bulent Unel. 2005. "Voluntary Association in Public Goods Experiments: Reciprocity, Mimicry and Efficiency." Economic Journal 115 (506): 1032-1053.

Rigdon, Mary L., Kevin A. McCabe, and Vernon L. Smith. 2007. "Sustaining Cooperation in Trust Games." Economic Journal 117 (522): 991-1007.

Rob, Rafael, and Peter Zemsky. 2002. "Social Capital, Corporate Culture, and Incentive Intensity." RAND Journal of Economics 33 (2): 243-257.

Salmon, Timothy C., and Roberto A. Weber. 2011. Maintaining Efficiency while Integrating Entrants from Lower-Performing Environments: An Experimental Study. Working Paper No. 35. University of Zürich.

Sutter, Matthias, Stefan Haigner, and Martin G Kocher. 2010. "Choosing the carrot or the stick? Endogenous institutional choice in social dilemma situations." The Review of Economic Studies 77 (4): 1540-1566. 
Svensson, Jakob. 2005. "Eight Questions about Corruption." Journal of Economic Perspectives 19 (3): 19-42.

Vesterlund, Lise. forthcoming. "Voluntary Giving to Public Goods." In Handbook of Experimental Economics, edited by John H. Kagel and Alvin E. Roth, 2:111-194. Princeton, New Jersey: Princeton University Press.

Weber, Roberto A. 2006. "Managing Growth to Achieve Efficient Coordination in Large Groups." American Economic Review 96 (1): 114-126. 


\section{Appendices}

\section{A. Simulation}

Fischbacher and Gächter (2010) (henceforth "FG") conduct an experiment in which subjects play a repeated public good game in four-person groups. Prior to the repeated game, FG elicit contribution schedules for all subjects, consisting of an amount contributed in response to every possible mean contribution by others. They also elicit subject beliefs concerning others' cooperation prior to each play of the game.

FG then use their experimental data to derive two functions that characterize behavior in the public good game played by subjects in their experiment. The first equation describes the evolution of beliefs about others' contributions as new information about past contributions becomes available through repeated play. The second equation translates these beliefs and the independently elicited contribution schedule into behavior. We first use FG's preferred specification of the two functions to conduct our simulation study, and vary these specifications later as a robustness check.

FG's preferred specification of the belief updating function states that the current belief of subject $i$ about others' average contributions, $b_{t, i}$, is a linear combination of the lagged belief, $b_{t-1, i}$, and lagged average contributions by other participants, $\bar{c}_{t-1,-i}$, plus a constant $\alpha_{b}$ :

$$
b_{t, i}=\alpha_{b}+\beta_{b} b_{t-1, i}+\gamma_{b} \bar{c}_{t-1,-i}
$$

FG estimate parameters $\hat{\alpha}_{b}=0.118, \hat{\beta}_{b}=0.569$ and $\hat{\gamma}_{b}=0.415$ as representative for participants in their experiment. Note that this equation characterizes the updating as a partial adaptation of the prior belief to new information. ${ }^{33}$ Crucially, this model is backward-looking and strategically myopic. That is, participants do not anticipate changes in the beliefs or contributions of other participants, or how their own actions may affect the behavior of others.

33. The sum of $\hat{\beta}_{b}$ and $\hat{\gamma}_{b}$ is close to, but slightly smaller than, one, so that the combination of the prior belief and new information are biased downward relative to a simple weighted average. The positive constant has a counteracting effect. 
Contributions, $c_{t, i}$, evolve over time as a linear function of a constant, $\alpha_{c}$, the subject's belief, $b_{t, i}$, about the others' contributions and an idiosyncratic contribution "preference," $f_{i}\left(b_{t, i}\right)$, which is the independently elicited profile of what the subject would like to give in a one-shot public good game, given her belief of what the others contribute:

$$
c_{t, i}=\alpha_{c}+\beta_{c} b_{t, i}+\gamma_{c} f_{i}\left(b_{t, i}\right)
$$

The parameters estimated by FG are $\hat{\alpha}_{c}=-0.473, \hat{\beta}_{c}=0.666$ and $\hat{\gamma}_{c}=0.242$. This means that contribution dynamics are driven by belief dynamics and the drift parameter $\left(\hat{\alpha}_{c}\right) \cdot{ }^{34}$ In all specifications, $\hat{\beta}_{c}+\hat{\gamma}_{c}$ is close to one.

In the FG data, there are two main types of subjects: freeriders with a flat contribution profile, and conditional cooperators with an increasing profile. The interaction between these two types drives down contributions over time, a commonly observed tendency in repeated public good experiments that is also reproduced by the model and simulation outlined in FG. We find the same result in our version of the simulation, that is, contributions finally drop to zero. The goal of our simulation exercise is therefore to see whether there is a difference between our experimental conditions after entrants have moved and before contributions have fully collapsed.

For our simulation, we randomly sampled the contribution profiles of six participants from the FG dataset, and simulated their participation in our experiment using FG's preferred belief updating process and the contribution schedules for those subjects. In the first period, we took each participant's unconditional prior belief, $b_{1, i}$, and combined it with her contribution function, $f_{i}\left(b_{1, i}\right)$, to determine initial contributions. ${ }^{35}$ Based on these initial contributions, the six participants were then divided into a two-person

34. This empirically estimated result is a little surprising because we would normally expect that a subject would act only on her preferences given her belief, that is, $c_{t, i}=f\left(b_{t, i}\right)$. As it turns out, the constant is not very precisely measured (i.e., it is statistically insignificant). Furthermore, if "confused" participants are removed and the first periods are dropped (as participants gain experience over time), both $\alpha_{c}$ and $\beta_{c}$ become considerably smaller and $\gamma_{c}$ considerably larger.

35. We replaced the actual contribution preferences $f_{i}\left(b_{t, i}\right)$ with their best linear fit $\hat{f}_{i}\left(b_{t, i}\right)$ to smoothen the simulation. This has a limited impact on the contribution schedules of both selfish participants and conditional cooperators, as these have linear schedules anyway, but affects the small minority of "triangle" contributors and confused participants. Results are virtually the same if this step is dropped. 
High group and a four-person Low group, as in Phase 2 of our behavioral experiment. Following our design, the six participants then played the game in these groups for 13 periods, corresponding to the ten periods of Phase 2 and the first three periods of Phase 3 (before growth) in our experiment. ${ }^{36}$ At the end of each period, participants observed the actual contributions by others in their group, and updated their beliefs about behavior in their own group according to the belief updating function.

Importantly, participants also held beliefs about contributions in the other group. That is, in each period, a subject, $i$, in the High group held beliefs $b_{t, i, H}^{H}$ about others' contributions in her own group, but also held beliefs about average contributions in the Low group, $b_{t, i, H}^{L}$, and vice versa. These two beliefs started from the same updated prior, at the end of period 1 , but diverged based on observed average contributions in the two groups. Both sets of beliefs updated according to the estimated belief updating equation discussed above.

For each of the sampled six-person groups, we then implemented movement from the Low group into the High group, starting in period 15. For each sampled group, we simulated participation in both our principal treatments. In a Fast Growth condition, we moved all four people from the Low group into the High group in period 15. In a Slow Growth condition, we moved one randomly selected subject into the High group in periods 15, 17, 19 and 20. Once growth was complete, we continued the simulation with participants playing in the merged six-person group until period 26.

While everything above closely follows the FG model, our simulation requires an assumption about how beliefs change when movement between groups occurs. In this case, we adopt the simple assumption that, when movement occurs, participants compute their beliefs for the groups with new composition as the average of the beliefs for the two separate groups, weighted by the incumbent-entrant composition faced by a subject in the new group. More precisely, suppose that $k_{t}$ individuals move in period $t$ from the Low

\footnotetext{
36. Importantly, the backward looking nature of the FG model precludes any possibility of "anticipation effects," whereby behavior changes due to knowledge of upcoming changes in group composition. To the extent that such behavioral effects are large and differ between Fast and Slow growth (which appears to be the case in our behavioral experiment), the simulation potentially underestimates the impact of variations in the growth rate.
} 
group into the High group, and group sizes were previously $n_{t}^{L}$ and $n_{t}^{H}$, respectively. Then, an incumbent subject in the High group first forms interim beliefs regarding expected contributions of those who were already in the High group in period $t-1$, based on observed outcomes in that prior period,

$$
\tilde{b}_{t, i, H}^{H}=\alpha_{b}+\beta_{b} b_{t-1, i, H}^{H}+\gamma_{b} \bar{c}_{t-1,-i}^{H},
$$

and also forms corresponding beliefs regarding the behavior of those who were previously in the Low group,

$$
\tilde{b}_{t, i, H}^{L}=\alpha_{b}+\beta_{b} b_{t-1, i, H}^{L}+\gamma_{b} \bar{c}_{t-1,-i}^{L} .
$$

Subject $i$ 's beliefs regarding behavior in the High group in period $t$ then simply weight these two interim beliefs by their corresponding proportion of the new High group population,

$$
b_{t, i, H}^{H}=\frac{n_{t-1}^{H}-1}{n_{t-1}^{H}+k_{t}-1} \tilde{b}_{t, i, H}^{H}+\frac{k_{t}}{n_{t-1}^{H}+k_{t}-1} \tilde{b}_{t, i, H}^{L} .
$$

Conversely, if a subject $i$ enters group $\mathrm{H}$ from group $\mathrm{L}$ in period $t$, he forms interim beliefs in the same way and then combines them according to:

$$
b_{t, i, L}^{H}=\frac{n_{t-1}^{H}}{n_{t-1}^{H}+k_{t}-1} \tilde{b}_{t, i, L}^{H}+\frac{k_{t}-1}{n_{t-1}^{H}+k_{t}-1} \tilde{b}_{t, i, L}^{L} .
$$

Thus, when a group transition occurs, participants form beliefs retrospectively about the expected contributions of the two kinds of members of the High group - entrants and incumbents - and then combine these two kinds of expectations using the relative number of the two populations in the High group. Since those departing from the Low group are selected at random, beliefs regarding behavior in the Low group are unaffected by group transitions and are updated as before.

We ran this simulation for 1'000 randomly sampled 6-person groups. The results provide evidence that high cooperation occurs more frequently under Slow growth than under Fast growth: 579 out of these 1'000 runs produce higher average contributions in the Slow condition than in the Fast condition, 355 runs produce lower average contributions, 
and 66 result in no difference.

To test the robustness of the results, we also ran the simulation using different combinations of weights, both in the belief updating function, $b_{t, i}$ and the contribution function, $c_{t, i}$, which are described above. Specifically, we varied the weights in increments of 0.01 , imposing the constraint that $\beta_{b}+\gamma_{b}=1$ (i.e., $\beta_{b}=0$ and $\gamma_{b}=1 ; \beta_{b}=0.01$ and $\gamma_{b}=0.99$; $\ldots)$. We also varied the weights in the contribution function $\left(\beta_{b}, \gamma_{b}\right)$ in the same manner. For each of these $10^{\prime} 000$ pairs of parameters, we simulated 1'000 groups of six participants, drawn randomly from the population of participants in FG's experimental dataset, running each group through both the Fast and the Slow conditions.

The result of this simulation exercise is presented in Figure 6. The weight on the lagged belief in the belief function, $\beta_{b}$, is on the x-axis, while the weight on the subject's preference in the contribution function, $\gamma_{c}$, is on the y-axis. As an indicator of whether the treatment is successful we count the number of simulations where average contributions in the Slow condition exceed average contributions in the Fast condition in period 21, after both groups attain a size of six. The line in the graph separates regions in which Slow growth outperforms Fast growth from those in which it does not. ${ }^{37}$ Below the line, contributions are higher in Slow than in Fast in more than 500 out of the 1'000 simulations for a particular parameter constellation-i.e., in this region we find support for our motivating hypothesis. ${ }^{38}$

The main result of the simulation is that, for sufficiently high weights on lagged beliefs, rather than play in the previous period, in the belief updating function (i.e., a tendency toward the right of the graph) and on beliefs, rather than preferences, in the contribution function (i.e., a downward tendency), average contributions are higher after Slow entry than after Fast entry. The main intuition underlying this result is that slow belief updating allows beliefs about cooperativeness in the High groups to be less influenced by drops in contributions immediately following growth, and it also helps when subjects act on their beliefs and underweight their one-shot contribution profile. In combination, these two

37. The line is smoothed using a median spline.

38. As mentioned above, contributions converge to zero in all cases, so that the difference we see here vanishes eventually. This is consistent both with FG's results and with the findings in our behavioral experiment. 
Figure 6: Simulation results for different parameter combinations. The diamond shows the preferred specification in FG. Below the line, more than 500 of 1'000 simulations yield higher average contributions in Slow than in Fast.

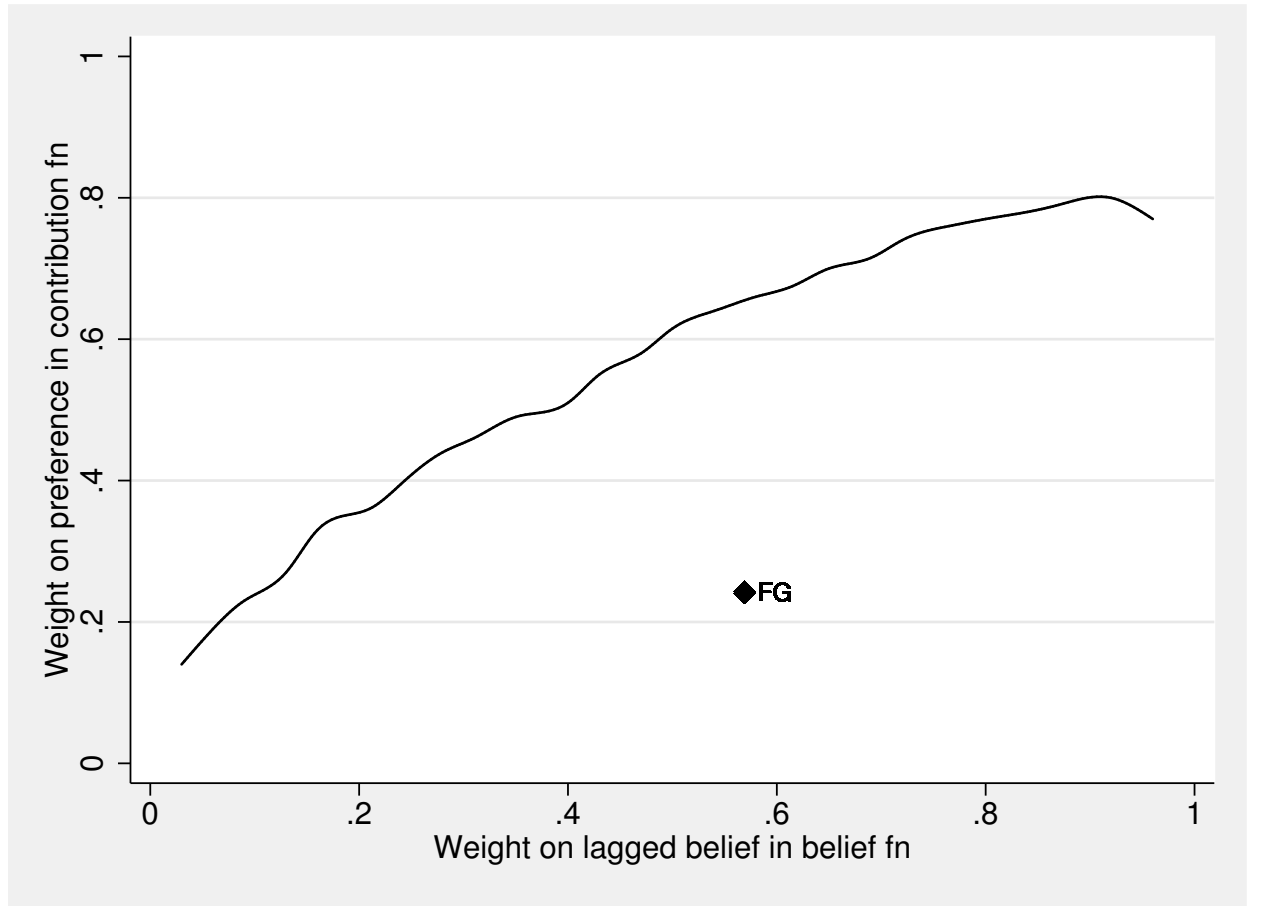

effects allow cooperation and beliefs in the High group to persist in the face of entrants with a lower propensity to contribute for a given set of beliefs.

\section{B. Instructions}

We present the complete instructions for the Voting condition, because this was the most complex of our conditions. The instructions for Fast and Slow, comprehension questions, questionnaire, and z-tree files are available upon request from the authors. 


\section{Initial Instructions}

Thank you for participating in today's experiment.

I will read through a script to explain to you the nature of today's experiment as well as how to navigate the computer interface with which you will be working. I will use this script to make sure that the information given in all sessions of this experiment is the same.

In addition to a $10 \mathrm{CHF}$ payment that you receive for your participation, you will be paid an amount of money that you accumulate from the decision task that will be described to you in a moment.

In total, the experiment comprises 36 periods of this decision task. At the end of the experiment, we will randomly select 6 of these periods to count for payment. Your final payment will consist of the money you accumulate from these 6 periods, plus the participation payment. The exact amount you receive will be determined during the experiment and will depend on your decisions and the decisions of others. You will be paid privately, in cash, at the conclusion of the experiment.

All monetary amounts you will see in this experiment will be denominated in ECU or Experimental Currency Units. We will convert ECU into CHF at the rate of

\section{$4 \mathrm{ECU}=1 \mathrm{CHF}$.}

If you have any questions during the experiment, please raise your hand and wait for an experimenter to come to you. Please do not talk, exclaim, or try to communicate with other participants during the experiment. Participants intentionally violating the rules may be asked to leave the experiment with only their participation payment.

At the beginning of today's experiment, all participants will be randomly assigned to a 6person group. Throughout today's experiment, you will only interact with the other 5 people in your group.

Today's experiment comprises three stages. Before each stage, you will receive the information necessary for that stage. 


\section{Stage $1($ Period 1)}

The first stage consists of one period of the decision task, during which you will interact with the other five people in your group.

\section{The Decision Task}

In each period, all participants begin with an endowment of 20 ECU. Each participant then decides how to allocate his or her 20 ECU between two accounts: a Private Account and a Common Account. The allocations to the Private Account and the Common Account must sum to $20 \mathrm{ECU}$ (your total endowment) in each period.

- The Private Account is your personal account. Any ECU that you allocate to this account belong to you. For every 1 ECU that you allocate to this account, you receive $1 \mathrm{ECU}$ at the end of the period.

- The Common Account is an account that is shared by all the members of the group. Each ECU allocated to the Common Account is multiplied by 2, and then divided evenly among the 6 group members. This means that for each ECU allocated to the Common Account, each group member receives $2 / 6=0.333$ ECU at the end of the period.

Your payoff from one period is thus calculated according to the formula:

$$
\begin{aligned}
\text { Payoff } \quad= & (20-\text { Your allocation to Common Account }) \\
& +(2 * \text { Total allocations to Common Account }) / 6
\end{aligned}
$$

The first part of this equation (20 - Your allocation to the Common Account) is what is left in your Private Account. The second part, $(2 *$ Total allocations to Common Account) / 6, is your share of the Common Account, after it is multiplied by 2 .

We refer to the multiplier 2 as the "return" from the Common Account.

Are there any questions about the decision task? 
The table below presents an example of how the payoffs from the task work. In the example, 3 participants each choose to allocate 20 ECU to the Common Account, and 3 participants each choose to allocate 0 ECU to the Common Account.

Assume that participants 1, 2, and 3 each put $20 \mathrm{ECU}$ in the Common Account and $0 \mathrm{ECU}$ in their Private Accounts. Participants 4, 5, and 6 put each 0 ECU in the Common Account and 20 ECU in their Private Accounts. These allocation choices are indicated in columns $\mathbf{B}$ and $\mathbf{C}$ in the table.

The total amount in the Common Account is then the sum of all the participants' allocations to this account, i.e. $20+20+20+0+0+0=60 \mathrm{ECU}$ (the total in column $\mathbf{C}$ ). These $60 \mathrm{ECU}$ in the Common Account are multiplied by the return, 2, which yields a total amount of 120 ECU. This total amount of $120 \mathrm{ECU}$ is then shared equally among the 6 group members, which means that each group member receives a share from the Common Account of $20 \mathrm{ECU}$ $(120 / 6=20$, column $\mathbf{D})$ that is part of his or her payoff in this period.

The total payoff for a participant in this period is then what that participant has put in his or her Private Account, plus his or her share of 20 ECU from the Group Account (columns $\mathrm{B}+\mathrm{D})$.

Participants 1, 2, and 3 thus each receive 20 ECU $(0+20=20$ ECU), and participants 4, 5, and 6 each receive $40 \mathrm{ECU}(20+20=40 \mathrm{ECU})$,

\begin{tabular}{|c|c|c|c|c|c|}
\hline A & B & C & & D & E \\
\hline $\begin{array}{c}\text { Participant } \\
\text { Number }\end{array}$ & $\begin{array}{c}\text { Allocation to } \\
\text { Private } \\
\text { Account }\end{array}$ & $\begin{array}{c}\text { Individual } \\
\text { Allocation to } \\
\text { Common Account }\end{array}$ & & $\begin{array}{c}\text { Individual Share } \\
\text { from Common } \\
\text { Account }\end{array}$ & $\begin{array}{c}\text { Total Payoff } \\
\text { for Period }\end{array}$ \\
\hline 1 & $\mathbf{0}$ & 20 & & $\mathbf{2 0}$ & $\mathbf{2 0}$ \\
\hline 2 & $\mathbf{0}$ & 20 & & $\mathbf{2 0}$ & $\mathbf{2 0}$ \\
\hline 3 & $\mathbf{0}$ & 20 & & $\mathbf{2 0}$ & $\mathbf{2 0}$ \\
\hline 4 & $\mathbf{2 0}$ & 0 & & $\mathbf{2 0}$ & $\mathbf{4 0}$ \\
\hline 5 & $\mathbf{2 0}$ & 0 & & $\mathbf{2 0}$ & $\mathbf{4 0}$ \\
\hline 6 & $\mathbf{2 0}$ & 0 & & $\mathbf{2 0}$ & $\mathbf{4 0}$ \\
\hline Group Total & & Sum $=60 \mathrm{ECU}$ & $\mathrm{X} 2$ & $=120 \mathrm{ECU}$ & $\begin{array}{c}\text { Sum } \\
=180 \mathrm{ECU}\end{array}$ \\
\hline
\end{tabular}

Are there any questions about this example? 
All group members decide privately and at the same time on their allocations between the Private and Common Accounts. You will make your choice by entering it into the computer. Once everyone has submitted his or her choice in a period, you will see a screen informing you about the outcome for that period.

Before you make your choice we will briefly describe the information that you will see on your screen when you make a decision. Click the "Continue" button on your screen now.

You should now see an important part of the screen you will be using to enter your choice. It is a calculator where you can test your possible payoffs, as a combination of your allocation to the Common Account and the average amount that the other members of the group allocate to the Common Account. You do this by entering an amount that you might want to allocate to the Common Account in the box named "Your Hypothetical Allocation to the Common Account", and a possible hypothetical value for the average allocation that you believe the other 5 group members might make to the Common Account, in the box named "Others' Hypothetical Average Allocation to the Common Account". Notice that, since your payoff depends only on your allocation to the Common Account and on the total allocation to the Common Account by others, the two numbers that you enter are all you need to calculate your possible payoff. (This is because the total allocation to the Common Account is equal to your allocation plus the average allocation by others multiplied by 5 .)

After entering these two amounts, you should then click on the "Test" button. You will then see the resulting hypothetical payoffs in a table similar to the table in the example. Please try entering two values now.

The columns in the table show allocations to the Private Accounts, allocations to the Common Account, the sum of allocations to the Common Account (your allocation $+5 *$ the average allocation by others), shares of the payment from the Common Account, and the total payoff in that period. The first row shows your own account allocations and resulting payoff. The other five rows show the corresponding average amounts for the other participants in your group. The rows for the other participants are all identical. This is because you only enter an average allocation for all the other participants together, instead of individual amounts. Because rows 2 to 6 are all the same, you will see a smaller table later on. You can see this smaller table below the bigger table on your screen.

You may try as many different values as you would like before making your choice, by entering different numbers and pressing the "Test" button again. It is important to remember that the actual average allocation by the other group members may be different than what you entered as a hypothetical value prior to making your decision. The actual average will be determined by the allocation choices of the other people in your group.

The payoff calculator will be available to you each time you make an allocation decision. Please try entering several possible values now, so that you become comfortable with the interface and with how the payoffs will work. Since your earnings in this experiment will 
depend on outcomes in this task, it is important that you understand how the payoffs are determined. If you are confused, please remember that your payoff from one period is calculated according to the formula:

$$
\begin{aligned}
\text { Payoff } \quad & (20-\text { Your allocation to Common Account }) \\
& +(2 * \text { Total allocations to Common Account }) / 6
\end{aligned}
$$

When you feel comfortable with the interface and with how payoffs are calculated, please click "Done". If you don't understand how to calculate the payoffs please raise your hand and an experimenter will come to you. 


\section{Stage 2 (Periods 2-11)}

The second stage comprises 10 periods. Please pay attention to the instructions, because the decision task will be a little different for Stage 2.

\section{Subgroups}

Based on the allocations in Stage 1, the participants in your group have been divided into two subgroups, called "H" and "L".

- Subgroup " $\mathrm{H}$ " consists of the 2 participants in your group that allocated the most to the Common Account in Stage 1.

- Subgroup " $L$ " consists of the 4 remaining participants in your group that allocated the least to the Common Account in Stage 1.

That is, the two participants in your group who allocated the most to the Common Account in Period 1 are in one subgroup ("H"), and the four people who allocated the least to the Common Account in Period 1 are in the other subgroup ("L"). If there are two or more identical allocations, these ties will be broken randomly. You will be informed about your group membership on your screen.

During Stage 2, the participants interact only with the members of their subgroup. Therefore, if you belong to the " $\mathrm{H}$ " subgroup, you will interact with 1 other participant. If you belong to the "L" subgroup, you will interact with 3 other participants. The Common Account will be replaced by two separate Accounts, one Common Account for the " $\mathrm{H}$ " subgroup and one Common Account for the "L" subgroup. Only the allocation choices of the other members of your subgroup will affect your payoff.

\section{The Return for the Common Account}

As before, in each period, all participants start with an endowment of 20 ECU and make a decision regarding how to allocate this sum between a Private Account and a Common Account for their subgroup. Each ECU allocated to your Private Account generates a payoff of 1, as before. However, each ECU allocated to the subgroup's Common Account is no longer multiplied by 2. Instead, the return for allocations to the Common Account varies with the number of participants in the subgroup, as indicated in the Table below.

- In a subgroup with 2 people, as in the "H" subgroup, the return for allocations to the subgroup's Common Account is 1.312. This means that every ECU allocated to the Common Account yields 1.312 ECU. This return is then divided evenly between the 2 people in the subgroup, yielding a per-person payoff of $1.312 / 2=0.656 \mathrm{ECU}$ for every ECU allocated to the Common Account. 
- In a subgroup with 4 people, as in the "L" subgroup, the return for allocations to the subgroup's Common Account is 1.620. This means that every ECU allocated to the Common Account yields 1.620 ECU. This return is then divided evenly among the 4 people in the subgroup, yielding a per-person payoff of $1.620 / 4=0.405 \mathrm{ECU}$ for every ECU allocated to the Common Account.

(It is not important for you to know this in order to make your choices, but we will tell you how we determined the return for different subgroup sizes. Remember that the return is 2.000 for a group with six participants. The return then decreases by $10 \%$ for each person by which the group size decreases, according to the formula Return $=2 * 90 \%{ }^{(6-N)}$. So, for a subgroup with four participants ("L"), Return $=2 * 90 \% * 90 \%=1.620$, and for a subgroup with two participants ("H"), Return $=2 * 90 \%{ }^{4}=1.312$.)

\begin{tabular}{|l|c|c|c|}
\hline Number of participants in (sub)group & 6 & 4 (“L”) & 2 ("H") \\
\hline Return for allocations to Common Account & 2.000 & 1.620 & 1.312 \\
\hline Per-person share of return & 0.333 & 0.405 & 0.656 \\
\hline
\end{tabular}

Note that the final amount in each subgroup's Common Account, after allocations are multiplied by the subgroup's return, is divided equally among the members of the subgroup.

Before each allocation decision you will receive the information necessary for your choice. A screen similar to the one in Stage 1 will provide you with information about the subgroup to which you belong, the number of participants in your subgroup, and the return for ECU allocated to the Common Account of your subgroup. You will also see a table with information on the outcomes in previous periods, including average Common Account allocations for the two subgroups. Once you are done examining the information, click "Continue".

As before, you can use the payoff calculator to explore different potential payoffs based on your allocation decision and the average Common Account allocation by others in your subgroup. The payoff calculator will take into account the specific return for your subgroup's Common Account when calculating payoffs.

Remember that you are only interacting with the other member or members of your subgroup. What happens in the other subgroup does not affect your payoff.

Are there any questions about the instructions for Stage 2? If so, please raise your hand. 


\section{Stage 3 (Periods 12-36)}

This stage lasts 25 periods. This is the final stage of the experiment, meaning that after the next 25 periods, the experiment will end.

The first 3 periods of Stage 3 (periods 12-14) will proceed identically to Stage 2. In these 3 periods, the 2 subgroups " $H$ " and "L" will interact separately in the same manner as in Stage 2 . The payoffs in a period will be determined exactly as in Stage 2 .

\section{Movement from Subgroup "L" to Subgroup " $H$ "}

Beginning with Period 15 and until Period 21, in each period, participants may be able to move permanently from subgroup " $\mathrm{L}$ " to subgroup " $\mathrm{H}$ ".

How many participants move in a period, if any, will be determined by a vote among those participants who are already in the " $\mathrm{H}$ " subgroup. That is, at the beginning of each period, from Period 15 to Period 21, members of subgroup " $\mathrm{H}$ " will decide, by voting, how many participants from subgroup " $\mathrm{L}$ " to move permanently into their group.

Voting will take place before participants make their allocation decisions in a period, and will determine the sizes of the 2 subgroups for that period. Voting will continue either until Period 21 or until there are no participants left in the subgroup " $L$ ".

Whenever members in the subgroup " $H$ " vote to move participants from the "L" subgroup into the " $\mathrm{H}$ " subgroup, a random draw will select which participants actually move, so that moving does not depend on allocations made in previous periods. This means that in a period in which there is movement from subgroup " $\mathrm{L}$ " to subgroup " $\mathrm{H}$ ", each participant in subgroup " $\mathrm{L}$ " is equally likely to move to subgroup " $H$ ".

\section{Voting by Subgroup “ $H$ ” Members}

The voting is done such that, at the beginning of a period, each participant in subgroup " $\mathrm{H}$ " indicates the number of participants that he or she wants to move from the "L" subgroup into the "H" subgroup. The actual number of participants who move is based on the median (middle) vote, and if the "High" subgroup consists of an even number of participants, the actual number is decided by the average of the middle pair of votes, randomly rounded to one of the nearest integers (whole numbers). 
Specifically,

- If subgroup " $\mathrm{H}$ " consists of 2 participants at the beginning of any period when there is voting, like in Period 15, each of these 2 participants indicates a number between 0 and 4 (since there are 4 participants in "L" subgroup at the beginning of that period). If the two "High" group members select the same number, then this will be the number of participants who move from the "L" to the " $H$ " subgroup. If they select different numbers, the average of the two numbers will be used. If the average is not an integer (whole number), it will be rounded to one of the nearest integers.

Example: If the two votes are: 1 and 4, then the average is 2.5 , meaning that either 2 or 3 participants move (the exact number is determined at random).

- If subgroup " $\mathrm{H}$ " consists of 3 participants at the beginning of any period when there is voting, each of these 3 participants indicates a number between 0 and 3 (since there are 3 participants in the "L" subgroup at the beginning of that period). The number of participants that moves is decided by the median (middle) vote.

Example: If the three votes are: 1, 2 and 2, then the middle vote is 2, meaning that 2 participants move.

- If subgroup " $\mathrm{H}$ " consists of 4 participants at the beginning of any period where there is voting, each of these 4 participants indicates a number between 0 and 2 (since there are 2 participants in the "L" subgroup at the beginning of that period). The number of participants that moves is decided by the average of the middle pair of votes, again if necessary randomly rounded to one of the nearest integers.

Example: If the four votes are: 0, 1, 2 and 2, then the average of middle votes is 1.5 , meaning that either 1 or 2 participants move (the exact number is determined at random).

- Finally, if subgroup "H" consists of 5 participants at the beginning of any period when there is voting, each of these 5 participants indicates the number 0 or 1 (since there is only 1 participant left in the "L" subgroup at the beginning of that period). Whether the one participant moves into the " $\mathrm{H}$ " subgroup is decided by the median (middle) vote, which in this case is also the vote selected by the majority.

Example: If the five votes are: $0,0, \mathbf{0}, 1$ and 1 , then the middle vote is 0 , meaning that the participant does not move.

Using this voting system, each participant does best by specifying the actual number of participants that he or she wants to move into the " $\mathrm{H}$ " subgroup. That is, there is no reason to try to manipulate your vote.

Each period from 15 to 21 starts by a vote, as long as there are participants left in the "L" subgroup. Following Period 21, the group or subgroups will remain fixed for the duration of the experiment, which lasts for an additional 15 periods, until Period 36. Should all 
participants have moved from the "L" subgroup to the " $H$ " subgroup before Period 21, the experiment continues until period 36 with all 6 participants in the "High" subgroup.

\section{The Return for the Common Account}

The return for allocations made to the Common Account in a period depends as in previous stages on the size of the (sub)group (See table below).

\begin{tabular}{|lcccccc|}
\hline Number of participants in (sub)group & 6 & 5 & 4 & 3 & 2 & 1 \\
\hline Return for allocations to Common Account & 2.000 & 1.800 & 1.620 & 1.458 & 1.312 & - \\
\hline Per-person return & 0.333 & 0.360 & 0.405 & 0.486 & 0.656 & - \\
\hline
\end{tabular}

A situation may arise in which there is only one participant in subgroup "L". In this case, there is no Common Account for subgroup "L" and this participant's 20 ECU endowment is automatically allocated to the Private Account. The single participant in subgroup "L" does not make any decision in this case and his or her period payoff is automatically set to 20 ECU.

As in the previous periods, you will receive the information necessary for your choice before each allocation or voting decision. For those periods in which you have to vote, the payoff calculator will let you test different payoffs for different group sizes. In addition to the payoff calculator, the choice screen also informs you about the subgroup to which belong, the number of participants in your subgroup, and the return on allocations to the Common Account. The screen also contains full information on previous average allocations for the relevant group or subgroups.

If you have any questions about Stage 3, please raise your hand and the experimenter will come to you. 